\title{
Nanoscale
}

Check for updates

Cite this: Nanoscale, 2017, 9, 7977

\section{Confining the spin between two metal atoms within the carbon cage: redox-active metal-metal bonds in dimetallofullerenes and their stable cation radicals $\uparrow$}

\author{
Nataliya A. Samoylova, (D) a Stanislav M. Avdoshenko, (D) a Denis S. Krylov, ${ }^{a}$

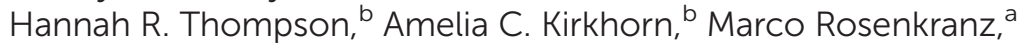 \\ Sandra Schiemenz, ${ }^{a}$ Frank Ziegs, ${ }^{a}$ Anja U. B. Wolter, ${ }^{a}$ Shangfeng Yang, (D) \\ Steven Stevenson (D) *b and Alexey A. Popov (D) *a
}

\begin{abstract}
Lanthanide-lanthanide bonds are exceptionally rare, and dimetallofullerenes provide a unique possibility to stabilize and study these unusual bonding patterns. The presence of metal-metal bonds and consequences thereof for the electronic properties of $\mathrm{M}_{2} \mathrm{AC}_{82}(\mathrm{M}=\mathrm{Sc}, \mathrm{Er}, \mathrm{Lu})$ are addressed by electrochemistry, electron paramagnetic resonance, SQUID magnetometry and other spectroscopic techniques. A simplified non-chromatographic separation procedure is developed for the isolation of $\mathrm{Er}_{2} \mathrm{CC}_{82}\left(C_{5}(6)\right.$ and $C_{3 v}(8)$ cage isomers) and $\mathrm{Sc}_{2} \mathrm{CC}_{82}\left(C_{3 v}(8)\right.$ isomer) from fullerene mixtures. Sulfide clusterfullerenes $\mathrm{Er}_{2} \mathrm{~S} \mathrm{C}_{82}$ with $C_{5}(6)$ and $C_{3 v}(8)$ fullerene cages are synthesized for the first time. The metal-metal bonding orbital of the spd hybrid character in $\mathrm{M}_{2} \mathrm{aC}_{82}$ is shown to be the highest occupied molecular orbital, which undergoes reversible single-electron oxidation with a metal-dependent oxidation potential. Sulfide clusterfullerenes with a fullerene-based HOMO have more positive oxidation potentials. The metal-based oxidation of $\mathrm{SC}_{2} \mathrm{aC}_{82}-\mathrm{C}_{3 \mathrm{v}}$ is confirmed by the EPR spectrum of the cation radical $\left[\mathrm{Sc}_{2} \mathrm{CC}_{82}{ }^{-}\right.$ $\mathrm{C}_{3 \mathrm{v}} \mathrm{J}^{+}$generated by chemical oxidation in solution. The spectrum exhibits an exceptionally large $a\left({ }^{45} \mathrm{SC}\right)$ hyperfine coupling constant of $199.2 \mathrm{G}$, indicating a substantial 4s contribution to the metal-metal bonding orbital. The cationic salt $\left[\mathrm{Er}_{2} \mathrm{aC}_{82}-\mathrm{C}_{3 \mathrm{~V}}\right]^{+} \mathrm{SbCl}_{6}{ }^{-}$is prepared, and its magnetization behavior is compared to that of pristine $\mathrm{Er}_{2} \mathrm{aC}_{82}-\mathrm{C}_{3 \mathrm{v}}$ and $\mathrm{Er}_{2} \mathrm{~S}_{\mathrm{aC}} \mathrm{C}_{82}-\mathrm{C}_{3 \mathrm{v}}$. The formation of the single-electron $\mathrm{Er}-\mathrm{Er}$ bond in the cation dramatically changes the coupling between magnetic moments of Er ions.
\end{abstract}

Received 31st March 2017, Accepted 4th May 2017

DOI: $10.1039 / \mathrm{c} 7 \mathrm{nr} 02288 \mathrm{c}$

rsc.li/nanoscale

\section{Introduction}

The magnetic and optical properties of lanthanides have earned them a plethora of practical applications and reinforce continuous exploration of the new possibilities the partiallyfilled 4f-shell can provide for academic and applied research in chemistry, physics, and materials science. The search for unusual oxidation states of lanthanides is one of the directions, in which the research is on-going. Over the last few

\footnotetext{
${ }^{a}$ Leibniz Institute for Solid State and Materials Research (IFW Dresden), Helmholtzstraße 20,01069 Dresden, Germany.E-mail: a.popov@ifw-dresden.de ${ }^{b}$ Indiana-Purdue University Fort Wayne, Department of Chemistry, 2101 E. Coliseum Blvd, Fort Wayne, IN 46835, USA. E-mail: stevenss@ipfiv.edu

${ }^{c}$ Hefei National Laboratory for Physical Sciences at Microscale, CAS Key Laboratory of Materials for Energy Conversion, Department of Materials Science and Engineering, University of Science and Technology of China, Hefei 230026, China $\dagger$ Electronic supplementary information (ESI) available. See DOI: 10.1039/ c7nr02288c
}

years, compounds with a formal +2 oxidation state, in which the lanthanide ion has a $4 \mathrm{f}^{n} 5 \mathrm{~d}^{1}$ electronic configuration, have been obtained for a majority of the lanthanide row. ${ }^{1-3}$ However, the synthesis of a molecular compound with covalent lanthanide-lanthanide bonds is still challenging for traditional organometallic chemistry. This obstacle can be circumvented by confining lanthanide ions within a limited space, such as the inner space of a fullerene molecule.

The encapsulation of metal atoms by carbon cages in the formation of endohedral metallofullerenes (EMFs) leads to a number of interesting chemical and physical phenomena, which have been attracting attention to EMFs over the last few decades. ${ }^{4-7}$ In EMFs, metal atoms transfer their valence electrons to the carbon cage. The EMFs can be then described as non-dissociative "salts", with endohedral metal atoms as cations and fullerene cages as anions. In dimetallofullerenes (di-EMFs, i.e. EMFs with two metal atoms), positively charged metal atoms repel each other. However, computational studies suggest that certain typically trivalent metal atoms form a 
metal-metal bonding orbital, whose energy is close to the energy of the frontier fullerene molecular orbitals (MOs). ${ }^{8,9}$ For early lanthanides such as La or Ce, this $\mathrm{M}-\mathrm{M}$ bonding orbital is usually the LUMO of the di-EMFs, which then leads to the special redox behavior of such fullerenes with relatively high reduction potentials. ${ }^{10-13}$ Upon reduction, the $\mathrm{M}-\mathrm{M}$ bonding MO is populated, and hence the metal-metal bond is formed. ${ }^{10}$ The formation of the single-occupied La-La bonding MO in the $\mathrm{La}_{2} @ \mathrm{C}_{80}{ }^{-}$anion radical is confirmed by EPR spectroscopy. ${ }^{14}$ Furthermore, the single-electron La-La bond has been stabilized in some non-charged derivatives of $\mathrm{La}_{2} @ \mathrm{C}_{80} .{ }^{15,16}$

In the case of Sc, Y, and late lanthanides (Er, $\mathrm{Lu}$ ), the $\mathrm{M}-\mathrm{M}$ bonding MO can be the HOMO of the respective di-EMF molecules, i.e., despite the strong Coulomb repulsion, there is a covalent bond between the metal atoms, which formally adopt a divalent state. ${ }^{8,17}$ The compounds with covalent lanthanidelanthanide bonds are not well known (metallic bonds in metals are not considered herein). In a recent exhaustive monograph on metal-metal bonding, multiple examples of bonding between transition metals or even between lanthanide and transition metals are discussed, but not a single example of a lanthanide-lanthanide bond is mentioned. ${ }^{18}$ The reason for this is that lanthanides usually tend to give their valence electrons away to make compounds with largely ionic bonding. Thus, EMFs provide a unique possibility to stabilize the lanthanide-lanthanide bonds inside carbon cages, which are not available otherwise.

Whether the M-M bonding MO in a given di-EMF involves the HOMO or the LUMO depends on the relative energies of the cage frontier MO and the energy of the metal-metal bonding orbital. Fig. 1 shows how the M-M bonding MOs in $\mathrm{Sc}_{2} @ \mathrm{C}_{82}$ and $\mathrm{Lu}_{2} @ \mathrm{C}_{82}$ evolve from the molecular orbitals of $\mathrm{Sc}_{2}$ and $\mathrm{Lu}_{2}$ dimers, respectively. The ground state of the $\mathrm{Sc}_{2}$ dimer is a quintet $(4 \mathrm{~s}) \sigma_{\mathrm{g}}{ }^{2}(3 \mathrm{~d}) \pi_{\mathrm{u}}{ }^{2}(3 \mathrm{~d}) \sigma_{\mathrm{g}}{ }^{1}(4 \mathrm{~s}) \sigma_{\mathrm{u}}{ }^{1}$, whereas $\mathrm{Lu}_{2}$ is a triplet $(6 \mathrm{~s}) \sigma_{\mathrm{g}}{ }^{2}(6 \mathrm{~s}){\sigma_{\mathrm{u}}}^{2}(5 \mathrm{~d}) \pi_{\mathrm{u}}{ }^{2}$ (i.e., the high spin states result in a significant splitting of the spin-up and spin-down orbitals of the same type).$^{19-22}$ The energy levels of the four highestenergy, singly-occupied MOs of both metal dimers are well above the energies of the LUMO and LUMO+1 of the empty $\mathrm{C}_{82}-C_{3 \mathrm{v}}(8)$ fullerene, and in the $\mathrm{M}_{2} @ \mathrm{C}_{82}-C_{3 \mathrm{v}}(8)$ molecule these four electrons are transferred from the metal dimers to the fullerene cage. At the same time, the two remaining valence electrons, which occupy $(4 \mathrm{~s}) \sigma_{\mathrm{g}}{ }^{2} \mathrm{MO}$ in $\mathrm{Sc}_{2}$ and $(6 \mathrm{~s}) \sigma_{\mathrm{g}}{ }^{2} \mathrm{MO}$ in $\mathrm{Lu}_{2}$, remain intact in di-EMFs because the energy of the corresponding $\mathrm{MO}$ is below the energy of the LUMO+2 of the empty $\mathrm{C}_{82}$ fullerene. As a result, we have $\mathrm{M}_{2} @ \mathrm{C}_{82}$ molecules with a 4 -fold charged carbon cage and the $\mathrm{M}-\mathrm{M}$ bonding HOMO resembling the $(n \mathrm{~s}) \sigma_{\mathrm{g}}{ }^{2} \mathrm{MO}$ of the corresponding metal dimer. Fig. 1 shows that the $(4 \mathrm{~s}) \sigma_{\mathrm{g}}{ }^{2} \mathrm{MO}$ in $\mathrm{Sc}_{2}$ and the HOMO of $\mathrm{Sc}_{2} @ \mathrm{C}_{82}$ have similar shapes. The dominant $\sigma$-character of the $\mathrm{M}-\mathrm{M}$ bonds in di-EMFs can be illustrated by the bond ellipticity, which amounts to 0.022 in $\mathrm{Sc}_{2} @ \mathrm{C}_{82}-C_{3 \mathrm{v}}(8), 0.042$ in $\mathrm{Y}_{2} @ \mathrm{C}_{82}-C_{3 \mathrm{v}}(8)$, and 0.050 in $\mathrm{Lu}_{2} @ \mathrm{C}_{82}-C_{3 \mathrm{v}}(8) .^{8}$ These values can be compared to the ideal $\sigma$-bond with zero ellipticity, or to $\mathrm{C}-\mathrm{C}$ bonds in benzene and ethylene with ellipticities of 0.23 and 0.45 , respectively.
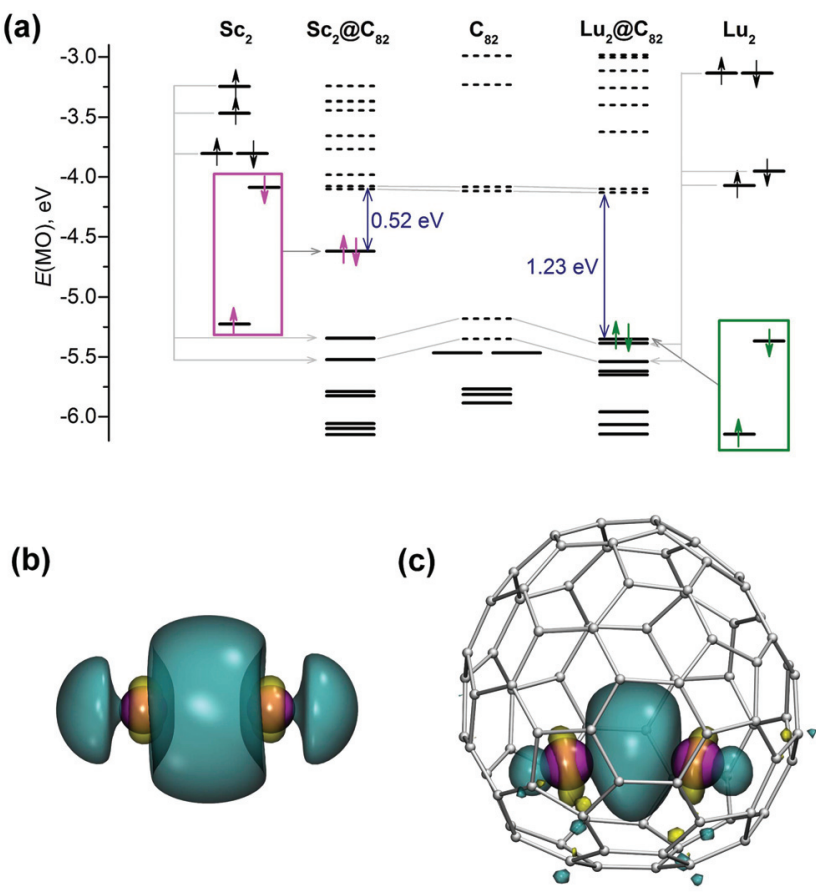

Fig. 1 (a) DFT-computed molecular orbital levels of the metal dimers $\mathrm{Sc}_{2}$ and $\mathrm{Lu}_{2}$, dimetallofullerenes $\mathrm{Sc}_{2} \mathrm{CC}_{82}$ and $\mathrm{Lu}_{2} \mathrm{CC}_{82}$, and the empty fullerene $C_{82}$; all fullerenes have the $C_{3 v}(8)$ cage isomer. Occupied levels are shown as solid lines, whereas unoccupied ones as dashed lines. Electrons at the $(n s) \sigma_{\mathrm{g}}{ }^{2} \mathrm{MOs}$ in the $\mathrm{M}_{2}$ dimers and the corresponding $M-M$ bonding orbital in the $M_{2} a_{82}$ molecules are highlighted in magenta $(M=S c)$ and green $(M=L u)$. (b) $(4 s) \sigma_{g}{ }^{2} M O$ in the $S c_{2}$ dimer. (c) The HOMO of the $\mathrm{Sc}_{2} \mathrm{aC}_{82}$ with a $\mathrm{Sc}-\mathrm{Sc}$ bonding character. In (b) and (c), Sc atoms are magenta, carbons are light grey, and MO isosurfaces are shown in cyan and dark yellow.

Thus, the HOMO energy in $\mathbf{M}_{2} @ \mathrm{C}_{82}$ is largely determined by the energy of the $(n \mathrm{~s}) \sigma_{\mathrm{g}}{ }^{2}$ orbital in the $\mathrm{M}_{2}$ dimer, which inversely correlates with the $n \mathrm{~s}^{2}(n-1) \mathrm{d}^{1} \rightarrow n \mathrm{~s}^{1}(n-1) \mathrm{d}^{2}$ excitation energy of the free metal atom: the higher the excitation energy, the lower the energy of the $(n \mathrm{~s}) \sigma_{\mathrm{g}}{ }^{2} \mathrm{MO}$. For instance, in the row La-Sc(Y)-Lu, the $n \mathrm{~s}^{2}(n-1) \mathrm{d}^{1} \rightarrow n \mathrm{~s}^{1}(n-1) \mathrm{d}^{2}$ excitation energies increase from $0.33 \mathrm{eV}$ in $\mathrm{La}$ to $1.43(1.36) \mathrm{eV}$ in $\mathrm{Sc}(\mathrm{Y})$ to $2.34 \mathrm{eV}$ in $\mathrm{Lu}$. The $(6 \mathrm{~s}) \sigma_{\mathrm{g}}{ }^{2} \mathrm{MO}$ in $\mathrm{La}_{2}$ has such a high energy that the vacant cage MOs are usually more stable and hence La adopts the true three-valent state in all known di-EMFs. The LaLa bonding MO is then the LUMO. The opposite situation is found in the Lu-di-EMFs: the $(6 \mathrm{~s}) \sigma_{\mathrm{g}}{ }^{2} \mathrm{MO}$ in $\mathrm{Lu}_{2}$ is so stabilized that Lu usually adopts a divalent state in Lu-di-EMFs, with the Lu-Lu MO being the HOMO or even lying below the HOMO level of the $\mathrm{Lu}_{2} @ \mathrm{C}_{2 n}$ molecule. With an intermediate value of the excitation energy, Sc can be either +3 (as in $\mathrm{Sc}_{2} @ \mathrm{C}_{66}{ }^{23}$ ) or +2 (as in $\mathrm{Sc}_{2} @ \mathrm{C}_{82}{ }^{9}$ ) depending on the fullerene cage. Similar behavior can be expected from $\mathrm{Y}$ and late lanthanides.

With the formal oxidation state of +2 , metal atoms have sufficiently large atomic charges (Bader analysis gives +1.25 for Sc, +1.37 for $\mathrm{Y}$, and +1.32 for $\mathrm{Lu}$ in respective $\mathrm{M}_{2} @ \mathrm{C}_{82}-C_{3 \mathrm{v}}(8)$ molecules $^{8}$ ), which lead to the large Coulomb repulsion between metal atoms. Evaluation of the "covalent" (exchange- 
correlation) and repulsion energies within the interactingquantum-atom approach in ref. 8 showed that Coulomb repulsion energies in $\mathrm{M}_{2} @ \mathrm{C}_{82}-C_{3 \mathrm{v}}(8)$ molecules are $c a .5 \mathrm{eV}$, which is opposed by the bonding energy of $c a .2 \mathrm{eV}$. Thus, the net M-M interaction in di-EMF with the $\mathbf{M}-\mathbf{M}$ bond is still strongly repulsive (ca. $3 \mathrm{eV}$ ), and such bonds would immediately dissociate if it were not the rigid environment of the fullerene cage, which fixes the metal ions at the bonding distances.

This introduction describes the current theoretical understanding of the possible metal-metal bonding situation in fullerenes. ${ }^{8}$ Surprisingly little is known experimentally about these unique systems, and even the charge state of metal atoms in the $\mathrm{M}_{2} @ \mathrm{C}_{82}$ molecules is a matter of debate. ${ }^{24-27}$ Meanwhile, if the M-M bonding orbital is indeed the HOMO of many dimetallofullerenes, it opens access to the manipulation of their spin state via redox chemistry. Creation of the single-electron bond between lanthanide ions having their own magnetic moment is an especially attractive goal. In this work, we report a detailed spectroscopic and electrochemical study of a series of $\mathbf{M}_{2} @ \mathrm{C}_{82}$ di-EMFs in comparison to their clusterfullerene analogs that lack the M-M bonding MOs. To make this study possible, Er-sulfide clusterfullerenes, $\operatorname{Er}_{2} \mathrm{~S} @ \mathrm{C}_{82}$ with $C_{\mathrm{s}}(6)$ and $C_{3 \mathrm{v}}(8)$ cage isomers, are synthesized for the first time; whereas for the dimetallofullerenes $\mathrm{Sc}_{2} @ \mathrm{C}_{82}$ and $\mathrm{Er}_{2} @ \mathrm{C}_{82}$, new non-chromatographic enrichment procedures have been developed to greatly simplify their isolation. Having the $\mathbf{M}-\mathbf{M}$ bonding nature of the orbitals verified, we generate the cation radicals $\mathrm{Sc}_{2} @ \mathrm{C}_{82}{ }^{+}$and $\mathrm{Er}_{2} @ \mathrm{C}_{82}{ }^{+}$with single-electron metal-metal bonds and characterize their unprecedented spin states by EPR spectroscopy and SQUID magnetometry.

\section{Results and discussion}

\section{Synthesis of EMFs}

To understand the influence of the metal on the energy of the M-M bonding orbitals in di-EMFs, we studied a series of dimetallofullerenes with different metals (Sc, Er, Lu) and Er sulfide clusterfullerenes with the same fullerene cages. Lu dimetallofullerenes were synthesized as minor products in the synthesis of Lu nitride clusterfullerenes and Lu-Ti carbide clusterfullerenes in the Lu/Ti/melamine system as reported earlier. ${ }^{28}$ HPLC separation afforded two $\mathrm{Lu}_{2} @ \mathrm{C}_{82}$ isomers. Likewise, small amounts of Er dimetallofullerenes and sulfide clusterfullerenes were isolated from an EMF mixture obtained by the arcdischarge synthesis of the Er metal and guanidine isocyanate. These synthetic conditions produce nitride clusterfullerenes $\mathrm{Er}_{3} \mathrm{~N} @ \mathrm{C}_{2 n}$ as the dominant EMFs, accompanied by a number of minor EMFs that include two isomers of dimetallofullerenes $\mathrm{Er}_{2} @ \mathrm{C}_{82}$ and two isomers of sulfide clusterfullerenes $\mathrm{Er}_{2} \mathrm{~S} @ \mathrm{C}_{82}$. Details of the chromatographic isolation and massspectroscopic characterization are given in the ESI. $\dagger$

\section{Non-chromatographic "catch and release" approach for $\mathbf{E r}_{2} @ \mathbf{C}_{82}$}

The HPLC separation of fullerene extract is often a tedious procedure that can easily require several weeks (see ref. 29 or the
ESI $\uparrow$ to this article for the separation of Er-EMFs using the conventional HPLC approach). Here we describe that a combination of non-chromatographic steps based on solubility and/ or reactivity differences of EMFs can substantially simplify the isolation. The solubility of $\mathrm{C}_{60}$ and $\mathrm{C}_{70}$ empty-cage fullerenes has been known for several decades, ${ }^{30}$ but little literature exists for the solubility of stable, metal-encapsulated fullerenes. Zhou et al. ${ }^{31}$ used solubility differences between $\mathrm{C}_{60}$ and $\mathrm{C}_{70}$ and optimized the solvent temperature to develop a separation method for their purification. ${ }^{31}$ Solubility differences for closed shell $\mathrm{C}_{74}$ empty-cage fullerenes and $\mathrm{Gd@} \mathrm{C}_{60}$ and $\mathrm{Gd@} \mathrm{C}_{74}$ endohedrals were used in the isolation of small-band gap fullerenes and metallofullerenes. ${ }^{32}$ In contrast, there is a lack of reports on utilizing solubility differences for purifying closed shell, dimetal endohedral metallofullerenes. For $\mathrm{Er}_{2} @ \mathrm{C}_{82}$, we report the benefit of using solubility differences to maximize its enrichment prior to HPLC fraction collection. We use the lower solubility of $\mathrm{Er}_{2} @ \mathrm{C}_{82}$ in xylenes relative to that of the dominant fullerene contaminants, $\mathrm{C}_{60}$ and $\mathrm{C}_{70}$. These empty-cage fullerenes have a higher solubility in xylenes and are preferentially dissolved and removed by the sequential addition of minimal solvent amounts until only $\mathrm{Er}_{2} @ \mathrm{C}_{82}$ isomers remain.

The $\mathrm{Er}_{2} @ \mathrm{C}_{82}$ and $\mathrm{Sc}_{2} @ \mathrm{C}_{82}$ samples used in this study originated from our "green chemistry" approach. ${ }^{33}$ A by-product of our non-chromatographic purification SAFA (Stir and Filter Approach) method for $\mathrm{Er}_{3} \mathrm{~N} @ \mathrm{C}_{80}$ and $\mathrm{Sc}_{3} \mathrm{~N} @ \mathrm{C}_{80}$ is spent aminosilica, which used to be discarded. This waste silica contained amine-reactive fullerenes and metallofullerenes that became immobilized onto the aminosilica during the $\mathrm{M}_{3} \mathrm{~N} @ \mathrm{C}_{80}$ purification process. Recovery of $\mathrm{Er}_{2} @ \mathrm{C}_{82}$ and $\mathrm{Sc}_{2} @ \mathrm{C}_{82}$ from the spent silica was reported by adding carbon disulfide ${ }^{33}$ to react with amine functionalized fullerenes to permit their release. As we describe herein, this "catch" of a fullerene with reactive silica and subsequent "release" of the fullerene can be developed into a non-chromatographic separation method.

The erbium metallofullerene extract was produced from the arc-synthesis method under a $\mathrm{He} / \mathrm{N}_{2}{ }^{34}$ atmosphere. Carbon disulfide extraction of the generated soot yielded a soluble extract containing $>90 \%$ empty-cage fullerenes, with $\mathrm{Er}_{2} @ \mathrm{C}_{82}$ and $\mathrm{Er}_{3} \mathrm{~N} @ \mathrm{C}_{80}$ being the dominant endohedrals. Two grams of this soot extract was dissolved in $1.8 \mathrm{~L}$ of xylenes, soaked overnight and filtered. Upon addition of $250 \mathrm{mg}$ of freshly vacuumed diaminosilica gel at $60{ }^{\circ} \mathrm{C}$ for $8 \mathrm{~h}$, the slurry was stirred for 4 days, at which time the reaction mixture was filtered to yield a filtrate of isomerically pure $\mathrm{Er}_{3} \mathrm{~N} @ I_{\mathrm{h}}-\mathrm{C}_{80} \cdot{ }^{33}$ Immediate washing of this spent silica with carbon disulfide and subsequent rotary evaporation provided $8 \mathrm{mg}$ of dried, $\mathrm{Er}_{2}$ @ $\mathrm{C}_{82}$ enriched sample. ${ }^{33}$ HPLC analysis of this $\mathrm{Er}_{2}$ @ $\mathrm{C}_{82}$ enriched sample is shown in Fig. 2a.

For this work, addition of $5 \mathrm{~mL}$ of the solvent was insufficient to dissolve the entirety of the $8 \mathrm{mg}$ of dried sample. To the undissolved fullerenes, another $5 \mathrm{~mL}$ of xylenes was added, with aliquots of the fullerenes being transferred into solution for monitoring by HPLC. After three successive additions of xylenes, the soluble fullerenes are shown in Fig. $2 \mathrm{~b}$, in which a significant reduction of $\mathrm{C}_{60}$ and $\mathrm{C}_{70}$ is 
a)

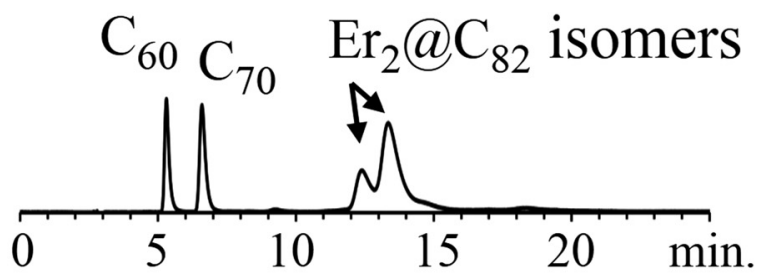

b)

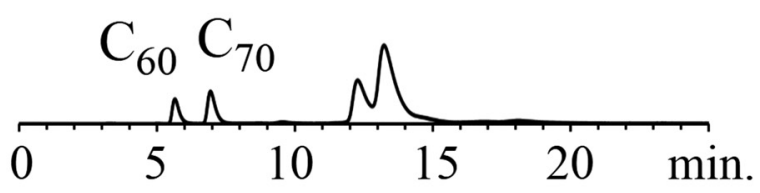

c)

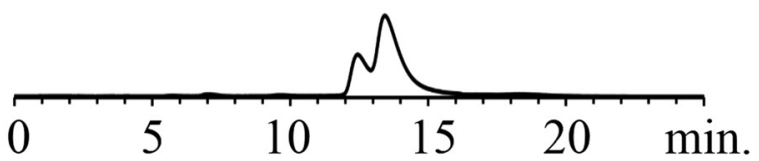

d)

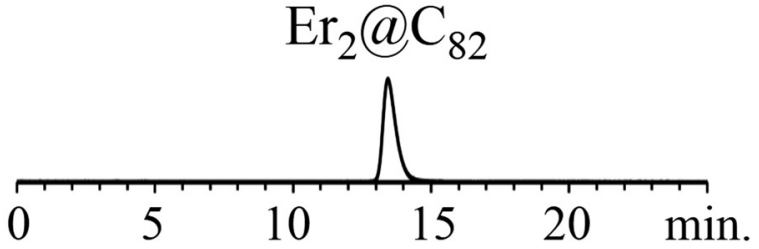

e)

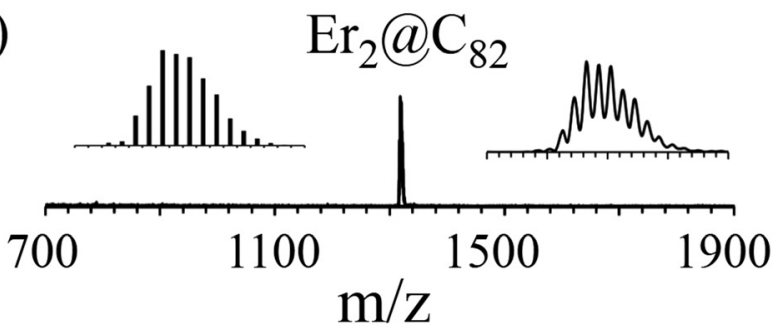

Fig. 2 HPLC results for $\mathrm{Er}_{2} \mathrm{CC}_{82}$ samples obtained from the (a) first addition of xylenes to the dried sample of fullerenes recovered from spent aminosilica, (b) after three successive additions of xylenes to the residual insoluble material, (c) after six more successive additions of xylenes, (d) after a final HPLC pass for final purification, and (e) LDI mass spectrum of purified $\mathrm{Er}_{2} \mathrm{AC}_{82}$. HPLC conditions were $1.0 \mathrm{~mL} \mathrm{~min}{ }^{-1}$ xylenes, BuckyPrep-M column, $360 \mathrm{~nm}$ UV detection and $250 \mu \mathrm{L}$ injection.

observed. Seeking further enrichment, this process of adding fresh xylenes to the undissolved fullerene sample was repeated six additional times to yield the chromatogram shown in Fig. 2c. Clearly the empty-cage contaminants have been removed. Being the dominant peak, purified $\mathrm{Er}_{2} @ \mathrm{C}_{82}$ can easily be efficiently obtained with a quick, final HPLC pass (Fig. 2d). The LDI mass spectrum shown in Fig. 2e confirms highly purified $\mathrm{Er}_{2} @ \mathrm{C}_{82}$ and matching experimental and theoretical isotope patterns.

\section{Non-chromatographic "catch and release" approach for $\mathrm{Sc}_{2}$ @C $\mathrm{C}_{82}$}

The isolation scheme for $\mathrm{Sc}_{2} @ \mathrm{C}_{82}$ is also newly reported. The selective reaction of a mixture containing $\mathrm{Sc}_{2} @ \mathrm{C}_{82}$ with $\mathrm{MgCl}_{2}$ yielded a significantly enriched sample of $\mathrm{Sc}_{2} @ \mathrm{C}_{82}$. Further $\mathrm{Sc}_{2} @ \mathrm{C}_{82}$ enrichment by the SAFA ${ }^{33,35-38}$ "catch and release" process provided a sample that contained primarily two species, $\mathrm{Sc}_{3} \mathrm{C}_{2} @ \mathrm{C}_{80}$ and $\mathrm{Sc}_{2} @ \mathrm{C}_{82}$. The scandium metallofullerene extract was also prepared and extracted in a similar manner to the erbium endohedrals.

As a first stage, $1 \mathrm{~L}$ of $\mathrm{CS}_{2}$ was added to a flask containing $1.3 \mathrm{~g}$ of the Sc fullerene extract, soaked overnight, PTFE membrane filtered, and the solution was transferred to a $2 \mathrm{~L}$ round bottom flask. The LDI mass spectrum of this extract solution is shown in Fig. 3a. To this stirring solution was immediately added $2.1 \mathrm{~g}$ of freshly opened anhydrous $\mathrm{MgCl}_{2}$. The reaction proceeded for $30 \mathrm{~h}$, at which time the reaction mixture was filtered. As previously described, fullerenes can be recovered from the precipitate via addition of multiple rinses with distilled water. ${ }^{38-44}$ Results from this work indicate three dominant fullerenes being recovered in decreasing order of the mass spectrum (Fig. 3b): $\mathrm{Sc}_{3} \mathrm{C}_{2} @ \mathrm{C}_{80}, \mathrm{Sc}_{4} \mathrm{C}_{2} @ \mathrm{C}_{80}$, and $\mathrm{Sc}_{2} @ \mathrm{C}_{82}$.

Stage two for isolating $\mathrm{Sc}_{2} @ \mathrm{C}_{82}$ was the "catch and release" of $\mathrm{Sc}_{2} @ \mathrm{C}_{82}$ from aminosilica. The $8 \mathrm{mg}$ of the $\mathrm{Sc}_{2} @ \mathrm{C}_{82}$-containing sample obtained after $\mathrm{MgCl}_{2}$ treatment was dissolved in $100 \mathrm{~mL}$ of freshly opened xylenes since a wet solvent and/or wet aminosilica affects the SAFA process. ${ }^{37}$ To this stirring solution was added $5 \mathrm{~g}$ of diaminosilica gel, which was freshly vacuum-oven dried overnight at $60{ }^{\circ} \mathrm{C}$. After 20 hours, the slurry was poured into a Buchner funnel. To the spent diaminosilica, still wet with xylenes, was added $600 \mathrm{~mL}$ of carbon disulfide to release the endohedrals as shown in Fig. 2c. The released sample contained a mixture of $\mathrm{Sc}_{2} @ \mathrm{C}_{82}$ and $\mathrm{Sc}_{3} \mathrm{C}_{2} @ \mathrm{C}_{80}$, which was then separated by HPLC giving pure $\mathrm{Sc}_{2} @ \mathrm{C}_{82}$ (Fig. S6 + ). Containing the endohedral fullerenes the

a)

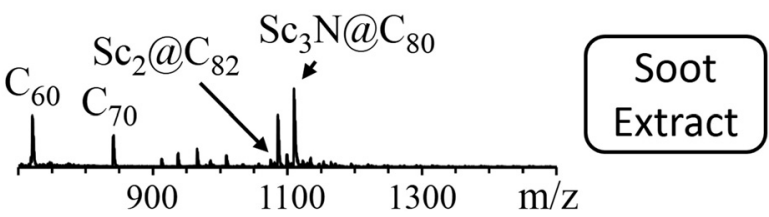

b)

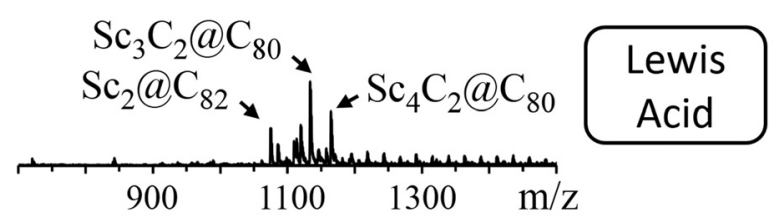

c)

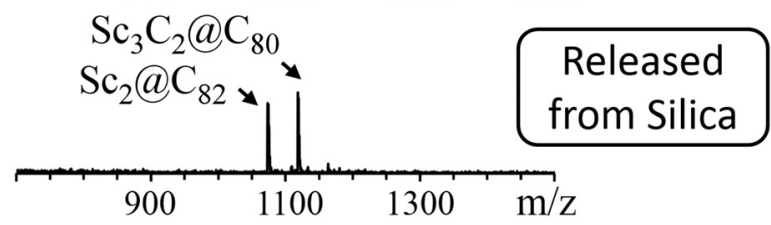

d)

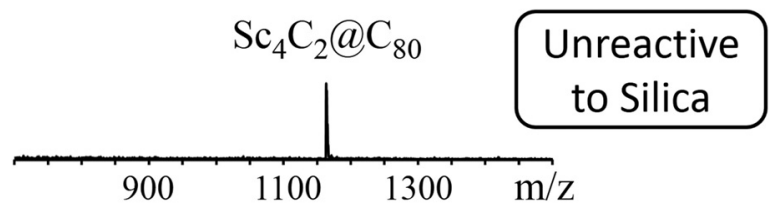

Fig. 3 LDI mass spectra for scandium endohedral metallofullerenes (a) in soot extract, (b) decomplexed with $\mathrm{H}_{2} \mathrm{O}$ after precipitation with $\mathrm{MgCl}_{2}$, (c) released from spent aminosilica with $\mathrm{CS}_{2}$, and (d) unreactive $\mathrm{Sc}_{4} \mathrm{C}_{2} \mathrm{aC}_{80}$ to aminosilica after $20 \mathrm{~h}$ of $\mathrm{Sc}_{2} \mathrm{aC}_{82}$ uptake. 
(a)

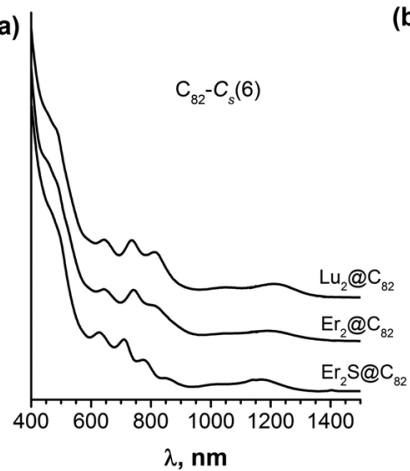

(b)

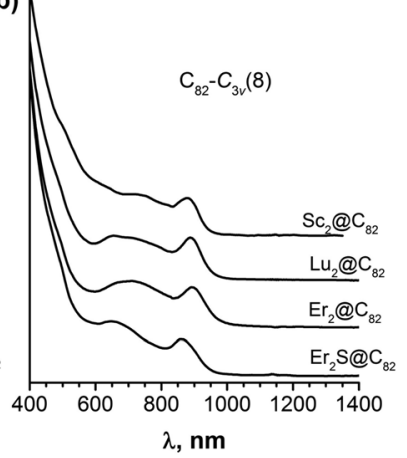

Fig. 4 Vis-NIR absorption spectra of EMFs: (a) isomers with a shorter retention time, assigned as $\mathrm{C}_{82}-C_{5}(6)$ and (b) isomers with a longer retention time, assigned as $C_{82}-C_{3 v}(8)$. For $\operatorname{Er}_{2} a_{82}-C_{3 v}(8)$, the molar extinction coefficients at $379 \mathrm{~nm}, 477 \mathrm{~nm}$, and $899 \mathrm{~nm}$ are determined to be $23.4 \times 10^{3}, 7.2 \times 10^{3}$, and $2.7 \times 10^{3}$, respectively

most inert to diaminosilica, the filtrate shows the chemical based isolation of $\mathrm{Sc}_{4} \mathrm{C}_{2} @ \mathrm{C}_{80}$ (Fig. 2d). This is a significant achievement as a non-chromatographic separation method for isolating the interesting $\mathrm{Sc}_{4} \mathrm{C}_{2} @ \mathrm{C}_{80}{ }^{45-48}$ has not yet been reported.

\section{Molecular structures of EMFs}

Molecular structures of two $\mathrm{Er}_{2} @ \mathrm{C}_{82}$ isomers with $C_{\mathrm{s}}(6)$ and $C_{3 \mathrm{v}}(8)$ carbon cages were elucidated earlier by single crystal X-ray diffraction. ${ }^{49,50}$ The molecular structure of the other EMFs can be established by vis-NIR absorption spectroscopy. Absorption spectra of EMFs are dominated by the $\pi-\pi^{*}$ transitions in the fullerene-based $\pi$-system and hence are very sensitive to the isomeric structure and the formal charge of the fullerene cage. Fig. 4 compares the spectra of the set of EMFs studied in this work; additional spectra are shown in the ESI (Fig. S11†). Despite the different composition of the endohedral species, all spectra can be classified into two groups with very similar spectra as shown in Fig. 4. Fig. 4a shows the spectra of the isomer with a shorter retention time, identified by its absorption pattern as $\mathrm{C}_{82}-C_{\mathrm{s}}(6)$; these spectra are also very similar to the spectra of $\mathrm{Sc}_{2} \mathrm{C}_{2} @ \mathrm{C}_{82}-C_{\mathrm{s}}(6),{ }^{51} \mathrm{Sc}_{2} \mathrm{~S} @ \mathrm{C}_{82^{-}}$ $C_{\mathrm{s}}(6),{ }^{52}$ and $\mathrm{Y}_{2} \mathrm{C}_{2} @ \mathrm{C}_{82}-C_{\mathrm{s}}(6) .{ }^{53}$ Fig. $4 \mathrm{~b}$ shows the spectra of the isomer with a longer retention time, identified as $\mathrm{C}_{82}-C_{3 \mathrm{v}}(8)$; very similar spectra were also reported for $\mathrm{Sc}_{2} \mathrm{~S} @ \mathrm{C}_{82}-C_{3 \mathrm{v}}(8),{ }^{52,54}$ or carbide clusterfullerenes $\mathrm{M}_{2} \mathrm{C}_{2} @ \mathrm{C}_{82}-C_{3 \mathrm{v}}(8)(\mathrm{M}=\mathrm{Sc}, \mathrm{Y}$, Er). ${ }^{26,53,55}$ Thus, absorption spectra allow unambiguous assignment of the isolated compounds to dimetallofullerenes or sulfide clusterfullerenes with $C_{\mathrm{s}}(6)$ and $C_{3 \mathrm{v}}(8)$ cage isomers with the 4 -fold charged fullerene. We will omit the (6) and (8) cage numbers in our further discussion and use only $C_{\mathrm{s}}$ and $C_{3 \mathrm{v}}$ notations to denote the isomers. The $\mathrm{C}_{82}{ }^{4-}$ state is natural for $\mathrm{Er}_{2} \mathrm{~S} @ \mathrm{C}_{82}$ when taking into account the formal $3+$ charge of the erbium ion and the 2- charge of the sulfide ion. For the $\mathrm{M}_{2}$ @ $\mathrm{C}_{82}$ molecules, the 4-fold charge of the cage indicates that the metal atoms have to be assigned a formal charge of $2+$, which agrees with the MO description depicted in Fig. 1 and implies the presence of the covalent $\mathrm{M}-\mathrm{M}$ bond.

\section{${ }^{13}$ C NMR spectroscopy}

Further confirmation of the molecular structure of $\mathrm{Lu}_{2} @ \mathrm{C}_{82^{-}}$ $C_{3 \mathrm{v}}$ is provided by ${ }^{13} \mathrm{C}$ NMR spectroscopy. The $\mathrm{C}_{82}-C_{3 \mathrm{v}}(8)$ fullerene is expected to have $17{ }^{13} \mathrm{C}$ NMR signals with an $11 \times 6,5 \times 3$, and $1 \times 1$ intensity pattern. In the experimental spectrum of $\mathrm{Lu}_{2}$ @ $\mathrm{C}_{82}-C_{3 \mathrm{v}}$ (Fig. 5a) we could identify all 6-fold and 3-fold intensity peaks, whereas the low-intensity peak due to the single carbon on the $C_{3}$ axis cannot be identified with the available signal-to-noise ratio. Similar but not identical ${ }^{13} \mathrm{C}$ NMR spectral patterns were reported for $\mathrm{Y}_{2} @ \mathrm{C}_{82}-C_{3 \mathrm{v}}{ }^{9}$ and $\mathrm{Sc}_{2}$ @ $\mathrm{C}_{82}-C_{3 \mathrm{v}} \cdot{ }^{53}$ The range of the ${ }^{13} \mathrm{C}$ shifts tends to decrease with the increase of the metal size. Together with the results of UV-vis-NIR spectroscopy, these data prove that $\mathrm{Lu}_{2} @ \mathrm{C}_{82}$ is a

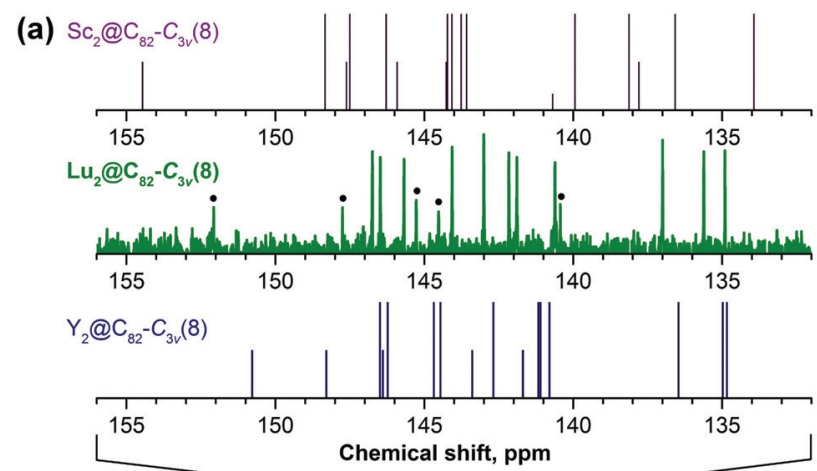

(b)

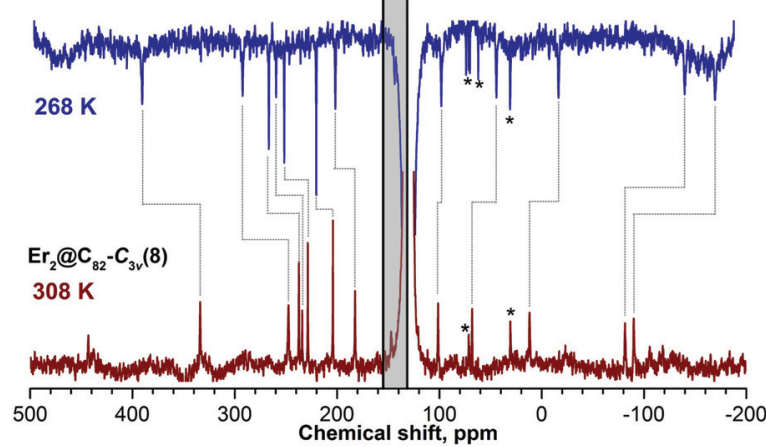

(c)

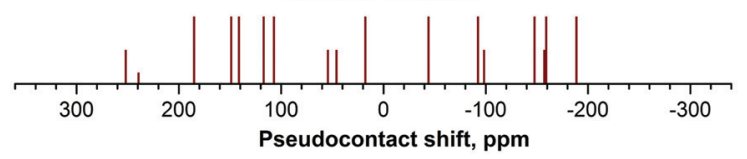

Fig. 5 (a) ${ }^{13} \mathrm{C}$ NMR spectrum of $\mathrm{Lu}_{2} @ \mathrm{CC}_{82}-C_{3 v}(8)$ compared to the spectra of $\mathrm{Sc}_{2} \mathrm{aC}_{82}-C_{3 \mathrm{v}}(8)$ and $\mathrm{Y}_{2} \mathrm{aC}_{82}-C_{3 \mathrm{v}}(8)$ shown as vertical lines with the shifts taken from ref. 9 and 53 respectively; half-intensity peaks of $\mathrm{Lu}_{2} \mathrm{QC}_{82}$ are marked with dots. (b) ${ }^{13} \mathrm{C}$ NMR spectra of $\mathrm{Er}_{2} \mathrm{aC}_{82}-\mathrm{C}_{3 \mathrm{v}}(8)$ measured at 268 and $308 \mathrm{~K}$, temperature shifts of the peaks are marked with grey lines. Asterisks denote the peaks assigned to impurities due to the lack of the temperature dependence; the strong peak at $131 \mathrm{ppm}$ is due to the solvent $\left(d^{4}-o\right.$-dichlorobenzene). The shaded area denotes the range of the chemical shifts in diamagnetic $\mathrm{M}_{2} \mathrm{aC}_{82}-C_{3 \mathrm{v}}(8)$ molecules. (c) Pseudocontact chemical shifts computed for $\mathrm{Er}_{2} \mathrm{aC}_{82}-C_{3 v}(8)$ and $T=300 \mathrm{~K}$ using eqn (2) and averaged over molecular dynamics trajectories. For the sake of comparison with experimental spectra, the zero point in (c) is positioned below the center of the range covering diamagnetic chemical shifts in $\mathrm{M}_{2} \mathrm{aC}_{82}-C_{3 \mathrm{v}}(\mathrm{M}=\mathrm{Y}, \mathrm{Lu})$. 
genuine dimetallofullerene and not the carbide clusterfullerene $\mathrm{Lu}_{2} \mathrm{C}_{2} @ \mathrm{C}_{80}$.

Paramagnetic ${ }^{13} \mathrm{C}$ NMR has been successfully applied for a number of Ce-EMFs ${ }^{13,56-58}$ and lanthanide nitride clusterfullerenes, ${ }^{59-61}$ and in this work ${ }^{13} \mathrm{C}$ NMR spectra have also been obtained for $\mathrm{Er}_{2} @ \mathrm{C}_{82}-C_{3 \mathrm{v}}$. Due to the paramagnetic influence of endohedral $\mathrm{Er}$ ions, ${ }^{13} \mathrm{C}$ chemical shifts in $\mathrm{Er}_{2} @ \mathrm{C}_{82}-C_{3 v}$ span the range of several hundred ppm and exhibit a pronounced temperature dependence. 12 of the 17 peaks could be identified with a high degree of certainty after variable-temperature NMR measurements in $\mathrm{d}^{4}$-o-dichlorobenzene (Fig. $5 \mathrm{~b}$ ). Chemical shifts of paramagnetic molecules include two contributions, i.e., diamagnetic $\left(\delta^{\mathrm{dia}}\right)$ and paramagnetic $\left(\delta^{\text {para }}\right): \delta^{\text {exp }}=\delta^{\text {dia }}+\delta^{\text {para }}$. The main contribution to the paramagnetic shifts in lanthanide-EMFs is the dipolar interactions of the lanthanide magnetic moment with carbon nuclear spins, also known as the pseudocontact shift $\delta^{\mathrm{pc}}$ :

$$
\begin{aligned}
\delta_{i}{ }^{\mathrm{pc}}= & \sum_{j} \frac{1}{12 \pi R_{i j}{ }^{3}}\left(\left(3 \cos ^{2} \theta_{i j}-1\right)\left(\chi_{z z}^{j}-\frac{\chi_{x x}^{j}+\chi_{y y}^{j}}{2}\right)\right. \\
& \left.+\frac{3}{2}\left(\chi_{x x}^{j}-\chi_{y y}^{j}\right) \sin ^{2} \theta_{i j} \cos 2 \varphi_{i j}\right)
\end{aligned}
$$

where $j$ runs through all lanthanide ions in the molecule, $\chi_{\alpha \alpha}^{j}$ are components of the magnetic susceptibility tensor of the $j$-th lanthanide ion, whereas $R_{i j}, \theta_{i j}$, and $\varphi_{i j}$ are polar coordinates of the $i$-th carbon atom in the coordinate system centered on the $j$-th lanthanide ion. In particular, $R_{i j}$ is the distance between them, and $\theta_{i j}$ is an angle between the quantization axis $z$ and the vector connecting the lanthanide ion and the $i$-th atom. In $\mathrm{Er}_{2} @ \mathrm{C}_{82}$, the magnetic susceptibility tensor of both Er ions can be considered identical; the quantization axis is aligned along the Er-Er bond, and $\chi_{x x}^{j}=\chi_{y y}^{j}$ (i.e. the ligand field is uniaxial). Then, eqn (1) is simplified to:

$$
\begin{aligned}
\delta_{i}^{\mathrm{pc}}= & \left(\chi_{z z^{\mathrm{Er}}}-\frac{\chi_{x x}^{\mathrm{Er}}+\chi_{y y}^{\mathrm{Er}}}{2}\right) \\
& \times\left(\frac{\left(3 \cos ^{2} \theta_{i 1}-1\right)}{12 \pi R_{i 1}{ }^{3}}+\frac{\left(3 \cos ^{2} \theta_{i 2}-1\right)}{12 \pi R_{i 2}{ }^{3}}\right) .
\end{aligned}
$$

Thus, interpretation of paramagnetic NMR spectra requires the knowledge of (i) the molecular structure and internal dynamics of the molecule and (ii) the magnetic anisotropy of the lanthanide ions. To address the first requirement, we performed DFT PBE/TZ2P calculations ${ }^{62,63}$ of the possible metal positions in the $\mathrm{Y}_{2} @ \mathrm{C}_{82}-C_{3 \mathrm{v}}$ and $\mathrm{Lu}_{2} @ \mathrm{C}_{82}-C_{3 \mathrm{v}}$ molecules, followed by Born-Oppenheimer molecular dynamics (BOMD) simulations for $\mathrm{Y}_{2} @ \mathrm{C}_{82} \mathrm{C}_{3 \mathrm{v}}$ at $300 \mathrm{~K}$ using the $\mathrm{CP} 2 \mathrm{~K}$ code $^{64,65}$ and PBE/DZVP level of theory. Y was used in simulations instead of Er to simplify the calculations. To obtain better statistics of the motion of metal atoms, three BOMD trajectories with different starting geometries were propagated for 75 ps. Fig. 6a shows the probability distribution of metal atoms inside the $\mathrm{C}_{82}-C_{3 \mathrm{v}}(8)$ cage obtained after joint analysis of all trajectories and taking the $C_{3 \mathrm{v}}$ symmetry of the cage into account. BOMD simulation shows that metal atoms rotate
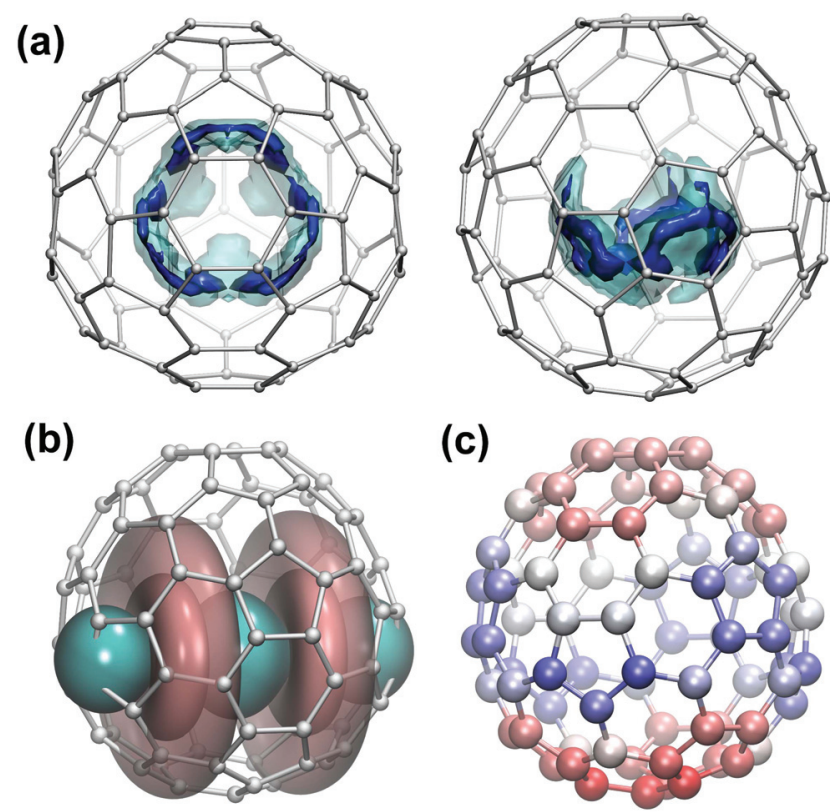

Fig. 6 (a) Probability distribution of metal atoms in $Y_{2}\left(a_{82}-C_{3 v}\right.$ at $300 \mathrm{~K}$ based on molecular dynamics simulations. The solid surface shows the high-probability regions (encompasses $60 \%$ of metal positions), transparent surface - lower probability (encompasses $98 \%$ of metal positions). (b) Pseudocontact chemical shift isosurfaces (at $\pm 1500 \mathrm{ppm}$, solid surfaces, and $+300 \mathrm{ppm}$, transparent surface) in $\mathrm{Er}_{2} \mathrm{OC}_{82}-C_{3 v}$ for a fixed position of metal atoms. (c) Distribution of ${ }^{13} \mathrm{C}$ pseudocontact chemical shifts in $\mathrm{Er}_{2} \mathrm{aC}_{82}-C_{3 \mathrm{v}}$ for a molecule with a rotating endohedral cluster. Color code: blue - negative values, red positive; intensity of the color corresponds to the size of the shift. Visualization of the isosurfaces is done with the VMD package. ${ }^{69}$

inside the cage, and high-probability metal positions form the belt around the equator of the molecule.

The magnetic susceptibility tensor was computed using the PHI code,${ }^{66}$ which employed crystal-field parameters obtained $a b$ initio at the CASSCF/SO-RASSI level using the SINGLE_ANISO module ${ }^{67}$ implemented in MOLCAS 8.0. ${ }^{68}$ The magnetic anisotropy term in eqn (2) is negative, which is normal for Er ions tending to have an easy-plane magnetization. Fig. $6 \mathrm{~b}$ shows the distribution of nuclear-independent chemical shifts in an $\mathrm{Er}_{2} @ \mathrm{C}_{82}-C_{3 \mathrm{v}}$ molecule computed using eqn (2) for the low-energy conformer. The large negative lobe is directed toward nearby carbon atoms at the equator, whereas the positive lobes are affecting carbons above and below the equator region. When the rotational dynamics of metal atoms are taken into account, the distribution of chemical shifts shown in Fig. $6 \mathrm{c}$ is obtained. Large negative shifts are distributed over the whole equator, whereas positive values are concentrated on the poles of the fullerene cage. A comparison with the experimental spectra (Fig. $5 \mathrm{~b}$ and c) shows that our computations are qualitatively correct as the computed chemical shifts span a similar range compared to experimental values, and pseudocontact shifts are equally distributed between positive and negative values. There are no very large shifts for any particular group of atoms, which proves that the 
internal dynamics of $\mathbf{M}_{2} @ \mathrm{C}_{82}-C_{3 \mathrm{v}}$ is captured correctly. However, an exact peak-to-peak assignment is hardly possible at this moment. The model adopted for computations is probably oversimplified, and the anisotropy of the susceptibility tensor appears to be underestimated. We suggest that the susceptibility tensor is weakly changing during the rotational motion of metal atoms, which may be a source of errors.

\section{Vibrational spectroscopy}

EMFs are characterized by low-frequency metal-based modes and isomer-specific cage vibrational patterns. Fig. 7 compares the Raman spectra of $\mathrm{Lu}_{2} @ \mathrm{C}_{82}, \mathrm{Er}_{2} @ \mathrm{C}_{82}$, and $\mathrm{Er}_{2} \mathrm{~S} @ \mathrm{C}_{82}$ with the $C_{3 \mathrm{v}}(8)$ cage. There is a pronounced similarity of the cage vibrations in the $200-1700 \mathrm{~cm}^{-1}$ frequency range, especially for dimetallofullerenes. A very close resemblance is also found for the IR spectra of $\mathrm{Lu}_{2} @ \mathrm{C}_{82}-C_{3 \mathrm{v}}$ and $\mathrm{Er}_{2} @ \mathrm{C}_{82}-C_{3 \mathrm{v}}$ (Fig. S12 $\dagger$ ), which serves as an additional proof of the same fullerene cage in both structures. The so-called "metal-cage stretching" vibrations of all three EMFs are found near $150 \mathrm{~cm}^{-1}$. The two

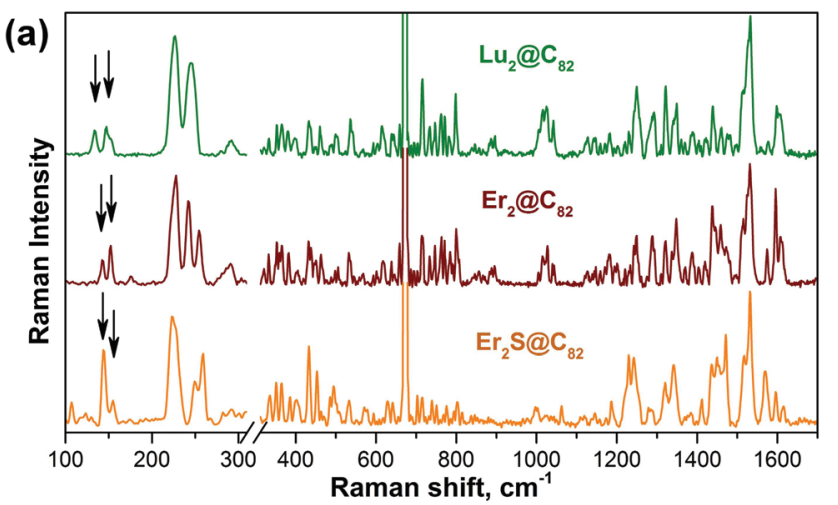

(b)
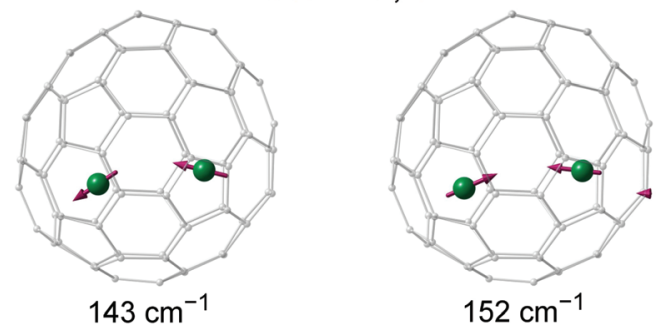

(c)
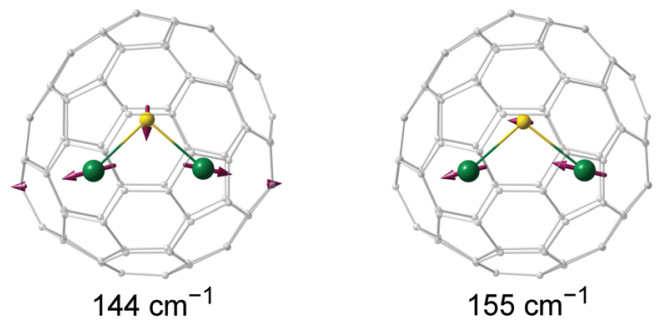

Fig. 7 (a) Raman spectra of $\mathrm{Lu}_{2} \mathrm{aC}_{82}-C_{3 \mathrm{v}}, \mathrm{Er}_{2} \mathrm{aC}_{82}-C_{3 \mathrm{v}}$, and $\mathrm{Er}_{2} \mathrm{~S} \mathrm{CC}_{82}-$ $C_{3 v}$ measured at $78 \mathrm{~K}$ and excited with a $647 \mathrm{~nm}$ laser line of the $\mathrm{Kr}^{+}$ laser; note the change of the frequency scale at $310 \mathrm{~cm}^{-1}$. Black arrows denote the peaks corresponding to the "metal-cage stretching" vibrations; the strong peak at $672 \mathrm{~cm}^{-1}$ is an instrumental artifact. (b) and (c) show atomic displacement patterns and frequencies for such vibrations in $\mathrm{Er}_{2} \mathrm{OC}_{82}-\mathrm{C}_{3 v}$ (b) and $\mathrm{Er}_{2} \mathrm{~S} \mathrm{CC}_{82}-C_{3 v}$ (c) (Er atoms are depicted in green, sulfur is yellow). peaks correspond to the in-phase and out-of-phase motions of metal atoms normal to the fullerene surface (Fig. $7 \mathrm{~b}$ and c). In the spectrum of $\mathrm{Lu}_{2} @ \mathrm{C}_{82}-C_{3 \mathrm{v}}$, the frequencies of these two modes are somewhat lower $\left(134 / 147 \mathrm{~cm}^{-1}\right)$ than in $\mathrm{Er}_{2} @ \mathrm{C}_{82^{-}}$ $C_{3 \mathrm{v}}\left(143 / 152 \mathrm{~cm}^{-1}\right)$, which is mainly caused by a large atomic mass of Lu. Interestingly, very similar frequencies for these modes (144/155 $\left.\mathrm{cm}^{-1}\right)$ are also found for the sulfide cluster, i.e. the presence of the Er-S bonds has seemingly no effect on the frequencies. A more detailed analysis based on DFT calculations of vibrational spectra shows that in $\mathrm{Er}_{2} \mathrm{~S} @ \mathrm{C}_{82}-C_{3 v}$, the out-of-phase motion occurs at a lower frequency than the inphase motion of Er atoms; whereas in the dimetallofullerenes the in-phase vibration has a lower frequency (Fig. 7c).

\section{Electrochemistry}

The experimental confirmation of the metal-metal bonding in di-EMFs is not very straightforward. The variation of the redox potentials in the series of di-EMFs and comparison to the redox potentials of clusterfullerenes with the same fullerene cages may be a method to shed some light on the problem. Molecular orbital analysis (Fig. 1) implies that the HOMO of $\mathrm{M}_{2} @ \mathrm{C}_{82}-C_{3 \mathrm{v}}$ molecules is the $\mathrm{M}-\mathrm{M}$ bonding orbital. The same type of the HOMO is predicted for $\mathrm{M}_{2} @ \mathrm{C}_{82}-C_{\mathrm{s}}$. Therefore, at the first oxidation step, the electron should be removed from this orbital. Since the energy of the M-M bonding MO correlates with the $n \mathrm{~s}^{2}(n-1) \mathrm{d}^{1} \rightarrow n \mathrm{~s}^{1}(n-1) \mathrm{d}^{2}$ excitation energy of the metal atom, the oxidation potential in the $\mathrm{M}_{2} @ \mathrm{C}_{82}$ compounds should be metal dependent (in both $C_{3 \mathrm{v}}$ and $C_{\mathrm{s}}$ cage isomers). In particular, $\mathrm{Lu}_{2} @ \mathrm{C}_{82}$ with its low energy of the LuLu bonding $\mathrm{MO}$ is expected to have higher oxidation potential than the $\mathrm{M}_{2} @ \mathrm{C}_{82}$ molecules with other metals. On the other hand, the LUMO of $\mathrm{M}_{2} @ \mathrm{C}_{82}$ is mainly localized on the fullerene cage, and hence the first reduction potential of $\mathrm{M}_{2} @ \mathrm{C}_{82}$ should be a metal-independent property of the cage. Electrochemical studies of $\mathrm{M}_{2} @ \mathrm{C}_{82}-C_{3 \mathrm{v}}$ and $\mathrm{M}_{2} @ \mathrm{C}_{82}-C_{\mathrm{s}}$ diEMFs described below fully agree with this reasoning.

In the cathodic range, all $\mathrm{M}_{2} @ \mathrm{C}_{82}-C_{3 \mathrm{v}}$ molecules behave similarly (Fig. 8a and Table 1). The first reduction near $-1.15 \mathrm{~V}$
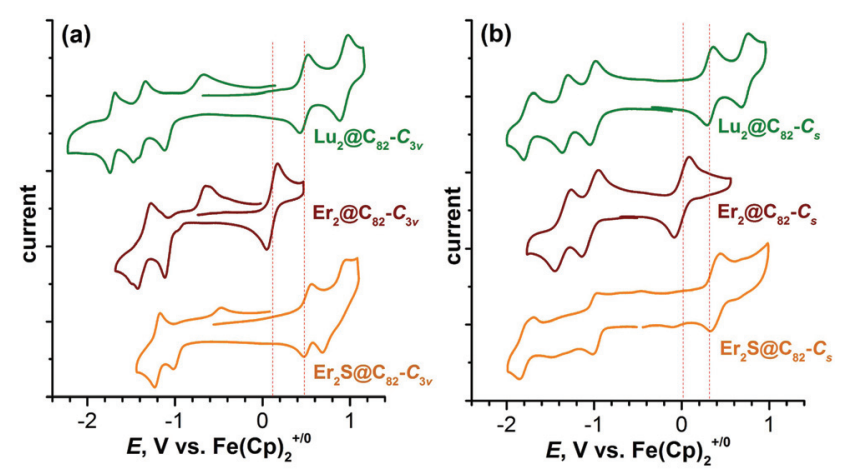

Fig. 8 Cyclic voltammetry of $\mathrm{Lu}_{2} \mathrm{QC}_{82}, \mathrm{Er}_{2} \mathrm{aC}_{82}$, and $\mathrm{Er}_{2} \mathrm{~S}_{3} \mathrm{CC}_{82}$ with $C_{3 v}(8)$ (a) and $C_{s}(6)$ (b) cage isomers. Scan rate $100 \mathrm{mV} \mathrm{s}^{-1}$, o-dichlorobenzene solution with the $\mathrm{TBAPF}_{6}$ electrolyte salt. Vertical dotted lines denote oxidation potentials of $\mathrm{Lu}_{2} \mathrm{AC}_{82}$ and $\mathrm{Er}_{2} \mathrm{CC}_{82}$. 
Table 1 Redox potentials of $\mathrm{M}_{2} \mathrm{aC}_{82}$ di-EMFs, $\mathrm{Er}_{2} \mathrm{~S}_{\mathrm{aC}} \mathrm{C}_{82}$, and selected Sc-clusterfullerenes with $\mathrm{C}_{82}-C_{3 \mathrm{v}}(8)$ and $\mathrm{C}_{82}-C_{\mathrm{s}}(6)$ cage isomers

\begin{tabular}{|c|c|c|c|c|c|c|c|}
\hline EMF & Ox-II & Ox-I & Red-I & Red-II & Red-III & $\mathrm{Gap}_{\mathrm{EC}}$ & Ref. \\
\hline $\mathrm{Lu}_{2} @ \mathrm{C}_{82}-C_{\mathrm{s}}(6)$ & 0.74 & 0.34 & -1.00 & -1.32 & -1.77 & 1.34 & t.w. \\
\hline $\mathrm{Sc}_{2} \mathrm{C}_{2} @ \mathrm{C}_{82}-C_{\mathrm{s}}(6)$ & 0.64 & 0.42 & -0.93 & -1.30 & - & 1.35 & 51 \\
\hline $\mathrm{Sc}_{2} \mathrm{O} @ \mathrm{C}_{82}-C_{\mathrm{s}}(6)$ & 0.72 & 0.35 & -0.96 & -1.28 & -1.74 & 1.31 & 73 \\
\hline $\mathrm{Sc}_{2} \mathrm{~S} @ \mathrm{C}_{82}-C_{\mathrm{s}}(6)$ & 0.65 & 0.39 & -0.98 & -1.12 & -1.73 & 1.37 & 73 \\
\hline $\mathrm{Er}_{2} @ \mathrm{C}_{82}-C_{3 \mathrm{v}}(8)$ & & 0.13 & -1.14 & -1.41 & -1.83 & 1.27 & t.w. \\
\hline $\mathrm{Lu}_{2} @ \mathrm{C}_{82}-C_{3 \mathrm{v}}(8)$ & 0.95 & 0.50 & -1.16 & -1.46 & -1.77 & 1.66 & t.w. \\
\hline $\mathrm{YLu} @ \mathrm{C}_{82}-C_{3 \mathrm{v}}(8)$ & & 0.23 & -1.13 & & & 1.36 & t.w. \\
\hline $\mathrm{Er}_{2} \mathrm{~S} @ \mathrm{C}_{82}-C_{3 \mathrm{v}}(8)$ & 0.88 & 0.51 & -0.98 & -1.21 & -1.70 & 1.49 & t.w. \\
\hline $\mathrm{Sc}_{2} \mathrm{C}_{2} @ \mathrm{C}_{82}-C_{3 \mathrm{v}}(8)$ & 0.93 & 0.47 & -0.94 & -1.15 & -1.60 & 1.41 & 74 \\
\hline $\mathrm{Sc}_{2} \mathrm{O} @ \mathrm{C}_{82}-C_{3 \mathrm{v}}(8)$ & 1.09 & 0.54 & -1.17 & -1.44 & -1.55 & 1.71 & 75 \\
\hline $\mathrm{Sc}_{2} \mathrm{~S} @ \mathrm{C}_{82}-C_{3 \mathrm{v}}(8)$ & 0.96 & 0.52 & -1.04 & -1.19 & -1.63 & 1.56 & 73 \\
\hline
\end{tabular}

All values are measured by square-wave voltammetry in $o$-dichlorobenzene solution and are referenced versus $\mathrm{Fe}(\mathrm{Cp})_{2}{ }^{+/ 0}$ redox pair; "t.w." denotes "this work".

is metal independent and proceeds irreversibly (the reoxidation peak is observed at $-0.7 \mathrm{~V}$ ). A double peak is observed at the second reduction step near -1.4/-1.5 V. For $\mathrm{Lu}_{2} @ \mathrm{C}_{82^{-}}$ $C_{3 \mathrm{v}}$, the third reversible reduction could also be observed at $-1.77 \mathrm{~V}$. The anodic behavior of $\mathrm{M}_{2} @ \mathrm{C}_{82}-C_{3 \mathrm{v}}$ is quite different. The first oxidation step is fully reversible, demonstrating the reasonable chemical stability of the cation radicals. Importantly, the oxidation potentials exhibit a pronounced metal-dependence, as expected for the metal-based HOMO. The least positive potential, $+0.02 \mathrm{~V}$, is recorded for $\mathrm{Sc}_{2} @ \mathrm{C}_{82^{-}}$ $C_{3 \mathrm{v}}$ (similar results were also reported for this molecule by Akasaka et al. $\left.{ }^{9}\right) . \mathrm{Er}_{2} @ \mathrm{C}_{82}-C_{3 \mathrm{v}}$ is the next in the row with the oxidation potential of $+0.13 \mathrm{~V}$. The oxidation of $\mathrm{Lu}_{2} @ \mathrm{C}_{82}-C_{3 \mathrm{v}}$ occurs at the much more positive potential of $+0.50 \mathrm{~V}$. Thus, whereas the first reduction potentials of the three $\mathrm{M}_{2} @ \mathrm{C}_{82}-C_{3 \mathrm{v}}$ molecules are virtually identical, the first oxidation step spans the range from +0.02 to $+0.50 \mathrm{~V}$.

The first reduction potentials of the $\mathrm{M}_{2} @ \mathrm{C}_{82}-C_{\mathrm{s}}$ di-EMFs are $-1.00 \mathrm{~V}(\mathrm{Lu})$ and $-1.01 \mathrm{~V}(\mathrm{Er})$. Importantly, for this cage isomer, the process is reversible as well as the second reductions near $-1.30 \mathrm{~V}$ (Fig. 8b). A reversible third reduction at $-1.77 \mathrm{~V}$ is also observed for $\mathrm{Lu}_{2} @ \mathrm{C}_{82}-C_{\mathrm{s}}$. Thus, the $\mathrm{M}_{2} @ \mathrm{C}_{82}$ isomers represent an interesting example of the isomer-dependent reversibility of the reduction. The irreversible reduction behavior of a majority of nitride clusterfullerenes was proved to be caused by the dimerization of their anion radicals. ${ }^{70,71}$ Presumably, EMFs with the $\mathrm{C}_{82}-C_{3 \mathrm{v}}(8)$ cage also dimerize in the anionic state, whereas the EMFs with the $\mathrm{C}_{82}-C_{\mathrm{s}}(6)$ cage do not. The cathodic behavior of $\mathrm{M}_{2} @ \mathrm{C}_{82}-C_{\mathrm{s}}$ is similar to that of the $\mathrm{M}_{2} @ \mathrm{C}_{82}-C_{3 \mathrm{v}}$ isomers. The first oxidation is reversible and shifts from $+0.02 \mathrm{~V}$ in $\mathrm{Er}_{2} @ \mathrm{C}_{82}-C_{\mathrm{s}}$ to $+0.34 \mathrm{~V}$ in $\mathrm{Lu}_{2} @ \mathrm{C}_{82}-C_{\mathrm{s}}$.

The significant variation of oxidation potentials in the $\mathrm{M}_{2} @ \mathrm{C}_{82}-\left(C_{3 \mathrm{v}}, C_{\mathrm{s}}\right)$ series with the metal and simultaneous metal-independence of the reduction potentials strongly support the MO description in Fig. 1. Further confirmation comes from the comparison to the clusterfullerenes with the same cage isomers (under the term "clusterfullerenes" we understand the EMFs with non-metal atoms in the endohedral species). Here we use $\mathrm{Er}_{2} \mathrm{~S} @ \mathrm{C}_{82}$ isomers isolated in this work as well as the literature data on $\mathrm{Sc}_{2} \mathrm{~S} @ \mathrm{C}_{82}, \mathrm{Sc}_{2} \mathrm{O} @ \mathrm{C}_{82}$, and $\mathrm{Sc}_{2} \mathrm{C}_{2} @ \mathrm{C}_{82}$ (Table 1). Fig. $\mathrm{S} 13$ in the ESI $\dagger$ compares the HOMO and LUMO of Sc-based clusterfullerenes with the $\mathrm{C}_{82}-C_{3 \mathrm{v}}$ cage to those of $\mathrm{Sc}_{2} @ \mathrm{C}_{82}-C_{3 \mathrm{v}}$. Unlike the metal-based HOMO of $\mathrm{Sc}_{2} @ \mathrm{C}_{82}-C_{3 \mathrm{v}}$, the HOMO of the clusterfullerenes is mainly localized on the fullerene. Therefore, their oxidation potentials are expected to be similar and give an upper bound for the diEMFs. The LUMOs of the $\mathrm{Sc}_{2} @ \mathrm{C}_{82}-C_{3 \mathrm{v}}, \mathrm{Sc}_{2} \mathrm{O} @ \mathrm{C}_{82}-C_{3 \mathrm{v}}$, and $\mathrm{Sc}_{2} \mathrm{~S} @ \mathrm{C}_{82}-C_{3 \mathrm{v}}$ are predominantly localized on the fullerene cage, albeit with a small but noticeable metal contribution, whereas the LUMO of the $\mathrm{Sc}_{2} \mathrm{C}_{2} @ \mathrm{C}_{82}-C_{3 \mathrm{v}}$ is localized on the carbide cluster. Thus, we can expect the reduction potentials of the di-EMFs and clusterfullerenes to be similar except for the $\mathrm{Sc}_{2} \mathrm{C}_{2} @ \mathrm{C}_{82}-C_{3 \mathrm{v}}$, which may have a more positive potential.

The experimental redox potentials listed in Table 1 are in line with the expectations based on the MO analysis. $\mathrm{Er}_{2} \mathrm{~S}_{2} \mathrm{C}_{82}-C_{3 \mathrm{v}}$ and Sc-based clusterfullerenes with the $\mathrm{C}_{82}-C_{3 \mathrm{v}}$ cage all have their first oxidation near $+0.5 \mathrm{~V}$, and this potential may be considered as an intrinsic property of the $\mathrm{C}_{82}-C_{3 \mathrm{v}}$ fullerene cage. Note that the oxidation potential of $\mathrm{Lu}_{2} @ \mathrm{C}_{82^{-}}$ $C_{3 \mathrm{v}}$ is quite close to this value. For $\mathrm{Lu}_{2} @ \mathrm{C}_{82} C_{3 \mathrm{v}}$, DFT predicts that the metal-based HOMO and the next cage-based MO have similar energies. Thus, it is not possible to distinguish if the oxidation of $\mathrm{Lu}_{2} @ \mathrm{C}_{82}$ proceeds via a cage- or metal-based $\mathrm{MO}$, but for $\mathrm{Sc}_{2} @ \mathrm{C}_{82}$ and $\mathrm{Er}_{2} @ \mathrm{C}_{82}$, the metal-based oxidation is unquestionable.

Reduction potentials of $\mathrm{Er}_{2} \mathrm{~S}_{0} @ \mathrm{C}_{82}-C_{3 \mathrm{v}}(-0.98 \mathrm{~V}), \mathrm{Sc}_{2} \mathrm{~S} @ \mathrm{C}_{82^{-}}$ $C_{3 \mathrm{v}}(-1.04 \mathrm{~V})$, and $\mathrm{Sc}_{2} \mathrm{C}_{2} @ \mathrm{C}_{82}-C_{3 \mathrm{v}}(-0.94 \mathrm{~V})$ are somewhat more positive than those of $\mathrm{M}_{2} @ \mathrm{C}_{82}-C_{3 \mathrm{v}}$, whereas $\mathrm{Sc}_{2} \mathrm{O} @ \mathrm{C}_{82^{-}}$ $C_{3 \mathrm{v}}$ has the most negative first reduction potential at $-1.17 \mathrm{~V}$. The span of these values agrees with the metal contributions to the LUMOs, from negligible in $\mathrm{Sc}_{2} \mathrm{O} @ \mathrm{C}_{82}-C_{3 \mathrm{v}}$ to the dominant in $\mathrm{Sc}_{2} \mathrm{C}_{2} @ \mathrm{C}_{82}{ }^{-} C_{3 \mathrm{v}}$ (Fig. S13 $\dagger$ ). Thus, we can postulate 
that $-1.17 \mathrm{~V}$ is the intrinsic reduction potential of the $\mathrm{C}_{82}-C_{3 \mathrm{v}}$ cage in EMFs with the 4-fold charge cluster, and more positive values evidence for the certain contribution of the metal atoms to the LUMO. Reduction potentials of $\mathrm{M}_{2} @ \mathrm{C}_{82}-C_{3 \mathrm{v}}$ at -(1.11-1.16) $\mathrm{V}$ indicate that metal atoms have a small contribution to the LUMO of these di-EMFs.

Very similar conclusions can be drawn from the redox potentials of EMFs with the $\mathrm{C}_{82}-C_{\mathrm{s}}$ cage isomer. The oxidation potentials of the clusterfullerenes at $0.35-0.42 \mathrm{~V}$ are slightly more positive than that of $\mathrm{Lu}_{2} @ \mathrm{C}_{82}-C_{\mathrm{s}}(+0.34)$, which indicates that the latter is probably oxidized via its Lu-Lu bonding HOMO. The first reduction potentials of the clusterfullerenes are slightly more positive than those of the di-EMFs and show that the fullerene has the dominant contribution to the LUMO of all these molecules. We should note, however, that the EPR study of the anion-radical of $\mathrm{Y}_{2} @ \mathrm{C}_{82}-C_{\mathrm{s}}(6)$ revealed a considerable ${ }^{89} \mathrm{Y}$ hyperfine coupling constant of $34.3 \mathrm{G},{ }^{72}$ which shows that the metal contribution to the LUMO is also substantial.

The metal dependence of the oxidation potential raises the question of how the HOMO energy will be affected in a mixedmetal system, especially when two metals with different electronic properties are combined in one molecule. To clarify this

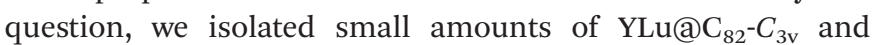
ErSc@ $\mathrm{C}_{82}-C_{3 \mathrm{v}}$ from the fullerene mixtures obtained in the synthesis of Y-Lu and Er-Sc nitride clusterfullerenes (see ref. 76 for details and the ESI $\dagger$ for sample characterization). Unfortunately, we could not isolate $\mathrm{Y}_{2} @ \mathrm{C}_{82}-C_{3 \mathrm{v}}$; although the compound was present in the fullerene mixture according to mass-spectral analysis, its HPLC isolation was found impossible due to the low stability. DFT calculations show that the HOMO energy of the $\mathrm{Y}_{2} @ \mathrm{C}_{82}-C_{3 \mathrm{v}}(-4.426 \mathrm{eV}$ at the PBE/TZ2P level) is even higher than that of $\mathrm{Sc}_{2} @ \mathrm{C}_{82}-C_{3 \mathrm{v}}(-4.676 \mathrm{eV}), \mathrm{so}$ for the former species, one can expect an oxidation potential near $0.0 \mathrm{~V}$ or more negative. Square-wave voltammetry shows that YLu@ $\mathrm{C}_{82}-C_{3 \mathrm{v}}$ is oxidized at $+0.23 \mathrm{~V}$ (Fig. 9), an intermediate value between the oxidation potential of $\mathrm{Lu}_{2} @ \mathrm{C}_{82}-C_{3 \mathrm{v}}$ and expected potential of $\mathrm{Y}_{2} @ \mathrm{C}_{82}-C_{3 \mathrm{v}}$. Likewise, the HOMO energy

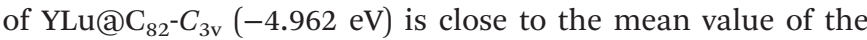
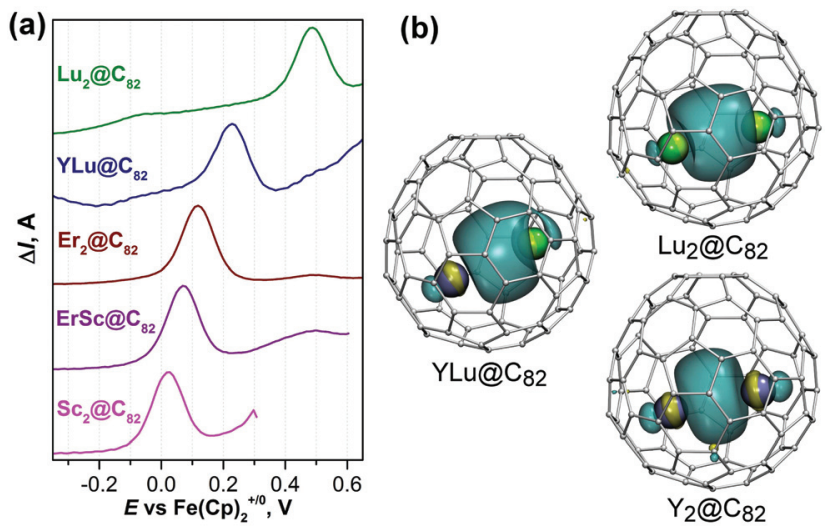

Fig. 9 (a) Square wave voltammetry of $\mathrm{Lu}_{2} \mathrm{CC}_{82}, Y L u @ C_{82}, \mathrm{Er}_{2} \mathrm{QC}_{82}$, ErSc@ $\mathrm{C}_{82}$, and $\mathrm{Sc}_{2} \mathrm{aC}_{82}$, all with the $C_{3 v}(8)$ cage, in the anodic range; (b) the HOMO isosurfaces in $\mathrm{Lu}_{2} \mathrm{aC}_{82}-C_{3 \mathrm{v}}, \mathrm{YLuAC}_{82}-C_{3 \mathrm{v}}$ and $\mathrm{Y}_{2} \mathrm{aC}_{82}-C_{3 \mathrm{v}}$.
HOMO energies of $\mathrm{Y}_{2} @ \mathrm{C}_{82}-C_{3 \mathrm{v}}(-4.426 \mathrm{eV})$ and $\mathrm{Lu}_{2} @ \mathrm{C}_{82}-C_{3 \mathrm{v}}$ $(-5.332 \mathrm{eV})$. Interestingly, the shape of the HOMO of $\mathrm{YLu} @ \mathrm{C}_{82}-C_{3 \mathrm{v}}$ has a pronounced asymmetry towards Lu (Fig. 9). Similarly, the oxidation potential of ErSc@ $\mathrm{C}_{82}-C_{3 \mathrm{v}}$ at $+0.08 \mathrm{~V}$ is found exactly between the potentials of $\mathrm{Sc}_{2} @ \mathrm{C}_{82}-C_{3 \mathrm{v}}(+0.02 \mathrm{~V})$ and $\mathrm{Er}_{2} @ \mathrm{C}_{82}-C_{3 \mathrm{v}}(+0.13 \mathrm{~V})$ (Fig. 9a).

\section{EPR spectroscopy}

Revealed in the electrochemical studies, the reversible oxidation of $\mathrm{Sc}_{2} @ \mathrm{C}_{82}$ and $\mathrm{Er}_{2} @ \mathrm{C}_{82}$ proves the stability of their cation radicals and opens the possibility for detailed studies of their properties. The oxidation of the $\mathbf{M}_{2} @ \mathrm{C}_{82}$ molecule via removal of one electron from the $\mathrm{M}-\mathrm{M}$ bonding $\mathrm{MO}$ leaves the cation radical with a large spin density localized on the metal atoms. When the metals are Sc, Y, or La, electron paramagnetic resonance (EPR) spectroscopy is especially convenient for the study of such radicals due to the rich hyperfine structure they may exhibit. The M-M bonding MO in di-EMFs inherits a large $n s$-contribution from the $(n \mathrm{~s}) \sigma_{\mathrm{g}}{ }^{2} \mathrm{MO}$ of the metal dimer, which leads to the large isotropic hyperfine coupling (hfc) constant. For instance, a huge $a\left({ }^{139} \mathrm{La}\right)$ hfc constant in the anion radical of $\mathrm{La}_{2} @ \mathrm{C}_{80}-I_{\mathrm{h}}$ as well as its paramagnetic derivatives prove the presence of the single-occupied La-La bonding MO in these species. ${ }^{14-16}$ Likewise, the EPR spectrum of $\mathrm{Y}_{2} @ \mathrm{C}_{79} \mathrm{~N}$ with its large $a\left({ }^{89} \mathrm{Y}\right)$ constant of $81.2 \mathrm{G}$ evidences the singleelectron $\mathrm{Y}-\mathrm{Y}$ bond in the azafullerene. ${ }^{77}$ The cation radical of $\mathrm{Sc}_{4} \mathrm{O}_{2} @ \mathrm{C}_{80}-I_{\mathrm{h}}$ exhibits a rich hyperfine structure due to the two pairs of equivalent Sc atoms with substantially different hfc constants, $2 \times 150.4$ and $2 \times 19.0 \mathrm{G}^{78}$ Particularly large $a\left({ }^{45} \mathrm{Sc}\right)$ values are explained by the $\mathrm{Sc}-\mathrm{Sc}$ bonding nature of the HOMO in $\mathrm{Sc}_{4} \mathrm{O}_{2} @ \mathrm{C}_{80}-I_{\mathrm{h}}$, which in fact resembles the HOMO of $\mathrm{Sc}_{2} @ \mathrm{C}_{82}-C_{3 \mathrm{v}}$ from this work. Note that the oxidation potentials of $\mathrm{Sc}_{4} \mathrm{O}_{2} @ \mathrm{C}_{80}-I_{\mathrm{h}}$ and $\mathrm{Sc}_{2} @ \mathrm{C}_{82}-C_{3 \mathrm{v}}$ are also quite close, 0.00 and $+0.02 \mathrm{~V}$, respectively.

The cation radical $\left[\mathrm{Sc}_{2} @ \mathrm{C}_{82}-C_{3 \mathrm{v}}\right]^{+}$was generated by a reaction of $\mathrm{Sc}_{2} @ \mathrm{C}_{82}-C_{3 \mathrm{v}}$ with tris(4-bromophenyl)aminium hexachloroantimonate (also known as "magic blue") in $o$-dichlorobenzene under the dry nitrogen atmosphere. The EPR spectrum measured at room temperature (Fig. 10) revealed a complex multi-line hyperfine structure spanning the range of $2800 \mathrm{G}$. Due to the large spectral width and relatively narrow line width of 1-3 $\mathrm{G}$ (requiring the use of a small modulation amplitude), acquisition of the spectrum took 2 days. After that, the intensity of the signal was found to decrease, presumably due to the degradation of the cation radical.

${ }^{45} \mathrm{Sc}$ has the nuclear spin of $7 / 2$, and the radical with two equivalent Sc atoms has a total nuclear spin of $I=I_{1}+I_{2}$, which spans integer values from 0 to 7 . In the first order of perturbation theory, positions of resonance lines in the EPR spectrum are dependent only on the projection of the total momentum, $m_{I}$, and the $\mathrm{Sc}_{2}$ dimer is expected to have 15 resonances in the EPR spectrum corresponding to $m_{I}=0, \pm 1, \ldots, \pm 7$. However, the experimental spectrum of $\left[\mathrm{Sc}_{2} @ \mathrm{C}_{82}-C_{3 \mathrm{v}}\right]^{+}$is much more complex and has as many as 64 lines (Fig. 10). The reason is that for the large hfc constants, the resonance positions are also dependent on the total momentum $I$, which 


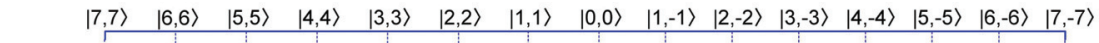

(a)

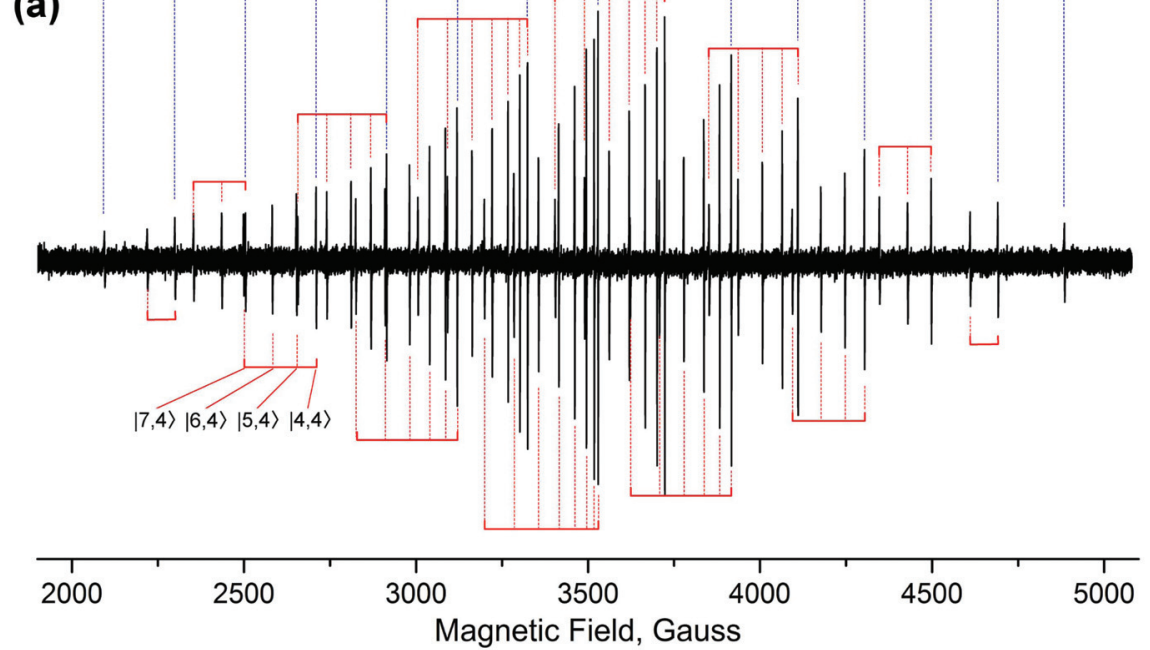

(b)

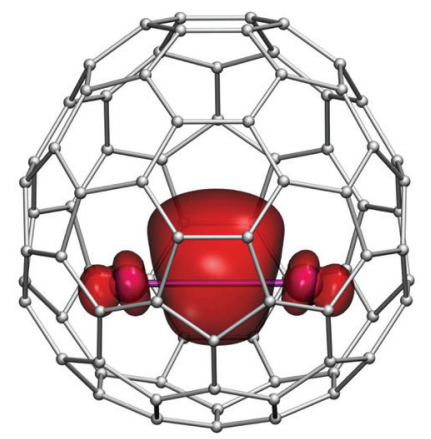

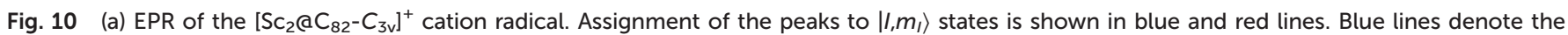

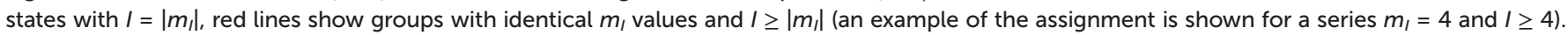
(b) DFT-computed spin density distribution in $\left[\mathrm{Sc}_{2} \mathrm{CC}_{82}-C_{3 \mathrm{v}}\right]^{+}$.

splits $15 m_{I}$-dependent lines into 64 lines with different $\left|I, m_{I}\right\rangle$ values. Despite the seemingly very complex hyperfine pattern, positions of all peaks can be well reproduced with a single $a\left({ }^{45} \mathrm{Sc}\right)$ constant of $2 \times 199.2 \mathrm{G}$ and a $g$-factor of 1.994 (see the ESI $\dagger)$. The $a\left({ }^{45} \mathrm{Sc}\right)$ constant in $\left[\mathrm{Sc}_{2} @ \mathrm{C}_{82}{ }^{-} C_{3 \mathrm{v}}\right]^{+}$is the largest among all Sc-based EMF radicals and is one of the largest among all Sc-based radicals in general. The isotropic hfc constant can be used to estimate the contribution of s-atomic orbitals of Sc to the spin density (and hence to the Sc-Sc bonding orbital). A ScO radical with an $a\left({ }^{45} \mathrm{Sc}\right)$ value of $630 \mathrm{G}$ is known to be a pure Sc-4s ${ }^{1}$ system. ${ }^{79}$ Using this as a reference, the contribution of Sc atomic 4s-orbitals to the spin density in $\left[\mathrm{Sc}_{2} @ \mathrm{C}_{82}-C_{3 \mathrm{v}}\right]^{+}$is determined to be $32 \%$, in reasonable agreement with the shape and orbital composition of the spin density calculated by DFT (Fig. 1). DFT calculations ${ }^{80,81}$ for the cation radical at the PBE/TZVP level also show that the position of the $\mathrm{Sc}_{2}$ unit has several minima with close energies, and the $\mathrm{Sc}_{2}$ dimer is probably rotating inside the cage. Average DFT-predicted $a\left({ }^{45} \mathrm{Sc}\right)$ values for different conformers of $\left[\mathrm{Sc}_{2} @ \mathrm{C}_{82}-C_{3 \mathrm{v}}\right]^{+}$are in the range of 163-173 G, and $g$-factors are 1.9948-1.9949, in reasonable agreement with experimental data. The hybrid nature of the Sc-Sc bonding orbital reveals itself in the angular momentum composition of the spin density: the Mulliken population analysis gives $52 / 24 / 24 \%$ for the contributions of $\mathrm{s} / \mathrm{p} / \mathrm{d}$ atomic orbitals of Sc, respectively, whereas the analysis according to the Löwdin scheme gives 23/ $36 / 34 \%$ for the same orbitals. Thus, different approaches to population analysis give substantially different angular momentum compositions, but both methods agree that all three types of atomic orbitals have a comparably large contribution.

After lifting the degeneracy, the intensity of all 64 lines in the isotropic spectrum should be identical. The experimental data (Fig. 10) obviously deviate from this expectation as the peaks close to the center have an apparently higher intensity. The reason for this pattern is the variation of the line width across the spectrum from $1.1 \mathrm{G}$ close to the center to $2.2 / 3.4 \mathrm{G}$ on the high- and low-field wings, which is caused by the incomplete rotational averaging (tumbling). Kivelson et al. found a quadratic or even cubic dependence of the line width on $m_{I}$ in the fast-motional regime. ${ }^{82,83}$ Indeed, analysis of the line widths in the EPR spectrum of $\left[\mathrm{Sc}_{2} @ \mathrm{C}_{82}-C_{3 \mathrm{v}}\right]^{+}$reveals this quadratic dependence on $m_{I}$ for the resonances with the same total momentum. For the lines with the same $m_{I}$ values, a quadratic dependence is also found on $I$. We hypothesize that for such rare systems with very large hfc values, the line-width in the fast-motional regime depends quadratically on $m_{I}$, and $I$ and should also include a mixed term. Fig. S16 in the ESI $\dagger$ shows that after fitting experimental line widths to a quadratic function of $m_{I}$ and $I$, the experimental spectrum can be perfectly reproduced by a simulated one.

\section{SQUID magnetometry}

The cation radicals $\left[\mathrm{Lu}_{2} @ \mathrm{C}_{82}-C_{3 \mathrm{v}}\right]^{+}$and $\left[\mathrm{Er}_{2} @ \mathrm{C}_{82}-C_{3 \mathrm{v}}\right]^{+}$did not show measurable EPR spectra in solution at room temperature, presumably due to the strong lanthanide-induced broadening of the lines. In the absence of EPR evidence on the spin density localization in these cation radicals, we addressed the issue using SQUID magnetometry. Changing the two-fold occupied Er-Er bonding orbital in $\mathrm{Er}_{2} @ \mathrm{C}_{82}$ to the single-occupied orbital in $\mathrm{Er}_{2} @ \mathrm{C}_{82}{ }^{+}$is expected to change the Er-Er exchange coupling and hence affect the magnetization behavior of the compound. For the magnetization studies, $\mathrm{Er}_{2} @ \mathrm{C}_{82^{-}}$ $C_{3 \mathrm{v}}$ was oxidized by an excess of magic blue in 0 -dichlorobenzene. The solvent was evaporated, and the residue was washed with acetonitrile to remove the excess of magic blue and then 
with toluene to remove unreacted $\mathrm{Er}_{2} @ \mathrm{C}_{82}-C_{3 \mathrm{v}}$. The remaining $\left[\mathrm{Er}_{2} @ \mathrm{C}_{82}-C_{3 \mathrm{v}}\right]^{+} \mathrm{SbCl}_{6}{ }^{-}$was then redissolved in $o$-dichlorobenzene and transferred to the SQUID capsule by drop-casting.

Fig. 11 compares the normalized magnetization curves measured for the powder samples of pristine $\mathrm{Er}_{2} @ \mathrm{C}_{82}-C_{3 \mathrm{v}}$ with the $\left[\mathrm{Er}_{2} @ \mathrm{C}_{82}-C_{3 \mathrm{v}}\right]^{+}$salt. The samples show a distinctly different magnetization behavior in magnetic fields below $2 \mathrm{~T}$. The increase of the magnetization with the increase of the external magnetic field is much faster for the cation than for the neutral $\mathrm{Er}_{2} @ \mathrm{C}_{82}-C_{3 \mathrm{v}}$. Note that the magnetization curve of the magic blue measured at the same temperature follows the Brillouin function with the spin $S=1 / 2$ and approaches the saturation value of the magnetization much slower than both EMF samples. Thus, the normalized magnetization curve for a mechanical mixture of magic blue and $\mathrm{Er}_{2} @ \mathrm{C}_{82}-C_{3 \mathrm{v}}$ would be also reaching saturation slower than $\mathrm{Er}_{2} @ \mathrm{C}_{82}-C_{3 \mathrm{v}}$ alone. Likewise, if oxidation would not affect the Er-Er interaction but only create an additional spin 1/2 localized on the carbon cage, the normalized magnetization curve of the $\left[\mathrm{Er}_{2} @ \mathrm{C}_{82}-C_{3 \mathrm{v}}\right]^{+}$cation would also be going below the curve of the pristine $\mathrm{Er}_{2} @ \mathrm{C}_{82}-C_{3 \mathrm{v}}$, similar to the mechanical mixture of $\mathrm{Er}_{2} @ \mathrm{C}_{82}-C_{3 \mathrm{v}}$ and magic blue. These arguments clarify that the difference in the magnetization curves of $\mathrm{Er}_{2} @ \mathrm{C}_{82}-C_{3 \mathrm{v}}$ and $\left[\mathrm{Er}_{2} @ \mathrm{C}_{82}-C_{3 \mathrm{v}}\right]^{+}$cannot be caused by an additional $S=1 / 2$ center weakly interacting with the lanthanide spin system, but has to have a lanthanide-based nature.

We can conclude that the oxidation of $\mathrm{Er}_{2} @ \mathrm{C}_{82}-C_{3 \mathrm{v}}$ by magic blue strongly modifies the spin state of the endohedral $\mathrm{Er}_{2}$ unit, presumably creating a three-center $\left[\mathrm{Er}^{3+}-\mathrm{e}-\mathrm{Er}^{3+}\right]$ system with stronger exchange interactions. Thus, our magnetization measurements confirm that the single-electron oxidation of $\mathrm{Er}_{2} @ \mathrm{C}_{82}-C_{3 \mathrm{v}}$ generates the cation with substantially modified Er-Er bonding, and can be interpreted in terms of the single-electron Er-Er bond. Interestingly, the magnetiza-

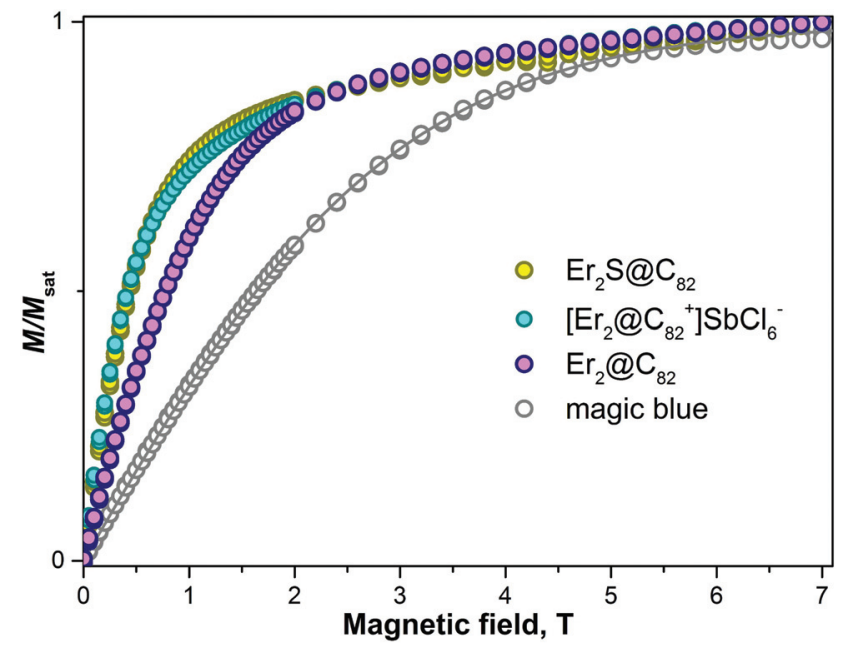

Fig. 11 Magnetization curves of $\mathrm{Er}_{2} \mathrm{~S} \mathrm{CC}_{82}-C_{3 \mathrm{v}}, \mathrm{Er}_{2} \mathrm{aC}_{82}-C_{3 \mathrm{v}},\left[\mathrm{Er}_{2} \mathrm{aC}_{82^{-}}\right.$ $\mathrm{C}_{3 \mathrm{v}} \mathrm{J}^{+} \mathrm{SbCl}_{6}{ }^{-}$, and magic blue at $T=2 \mathrm{~K}$. For each sample, the curve was normalized to the value measured at $7 \mathrm{~T}$. The line shows Brillouin function with the spin $S=1 / 2$ fitting the data points for magic blue. tion curve of $\left[\mathrm{Er}_{2} @ \mathrm{C}_{82}-C_{3 \mathrm{v}}\right]^{+}$at $2 \mathrm{~K}$ closely follows that of the $\mathrm{Er}_{2} \mathrm{~S} @ \mathrm{C}_{82}-C_{3 \mathrm{v}}$ (Fig. 11).

$A b$ initio calculations (see the ESI $\dagger$ ) show that in both $\mathrm{Er}_{2} @ \mathrm{C}_{82}-C_{3 \mathrm{v}}$ and $\mathrm{Er}_{2} \mathrm{~S} @ \mathrm{C}_{82}-C_{3 \mathrm{v}}$, the $\mathrm{Er}$ ions have an easy-plane single-ion anisotropy. The crystal field splitting in both systems is sufficient to ensure that the magnetization behavior at $2 \mathrm{~K}$ is determined solely by the ground-state properties. Therefore, the large difference between $\mathrm{Er}_{2} @ \mathrm{C}_{82}-C_{3 \mathrm{v}}$ and $\mathrm{Er}_{2} \mathrm{~S} @ \mathrm{C}_{82}-C_{3 \mathrm{v}}$ is caused by how magnetic moments of individual Er centers are coupled, and not by the single-ion properties. Non-collinear orientation of the magnetic axes in $\mathrm{Er}_{2} \mathrm{~S} @ \mathrm{C}_{82}-C_{3 \mathrm{v}}$ should also play a certain role. The similarity of the magnetization behavior of $\left[\mathrm{Er}_{2} @ \mathrm{C}_{82}-C_{3 \mathrm{v}}\right]^{+}$and $\mathrm{Er}_{2} \mathrm{~S} @ \mathrm{C}_{82^{-}}$ $C_{3 \mathrm{v}}$ in due turn indicates that the magnetic coupling between Er centers becomes comparable. A more detailed analysis of the magnetization data of $\mathrm{Er}_{2} @ \mathrm{C}_{82}-C_{3 \mathrm{v}}$ and $\left[\mathrm{Er}_{2} @ \mathrm{C}_{82}-C_{3 \mathrm{v}}\right]^{+}$ would be premature at this moment as it requires a better understanding of the crystal field splitting experienced by the $\mathrm{Er}$ ions in the neutral and cationic forms of $\mathrm{Er}_{2} @ \mathrm{C}_{82}-C_{3 \mathrm{v}}$ as well as the modelling of the exchange interactions. Such measurements and calculations are currently underway in our group and will be reported in due time.

\section{Conclusions}

The unusual oxidation states of lanthanides have attracted considerable attention, and compounds with divalent states and $4 \mathrm{f}^{n} 5 \mathrm{~d}^{1}$ electronic configurations have been reported for almost the entire lanthanide row. ${ }^{1-3}$ Compounds in which two lanthanide ions have an unusual oxidation state and form an intermetallic bond are synthesized so far only for dimetallofullerenes, such as the $\mathbf{M}_{2} @ \mathrm{C}_{82}$ species studied in this work. For these molecules, two lanthanide ions in a formal divalent state form a lanthanide-lanthanide bond via a $\sigma$-bonding orbital of the spd-hybrid character. The metal-metal bonding MO is the HOMO in di-EMFs such as $\mathrm{Er}_{2} @ \mathrm{C}_{82}$, and is prone to a oneelectron oxidation with the formation of stable cation radicals with single-electron metal-metal bonding. Electrochemical studies of $\mathrm{M}_{2} @ \mathrm{C}_{82}$ di-EMFs and a comparison to the redox behavior of clusterfullerenes having the same fullerene cages fully prove this point. The definitive proof of the metal-based oxidation of $\mathrm{Sc}_{2}$ @ $\mathrm{C}_{82}-C_{3 \mathrm{v}}$ is provided by EPR spectroscopy of the cation radical, which shows a giant isotropic ${ }^{45} \mathrm{Sc}$ hyperfine coupling constant of $199.2 \mathrm{G}$. The unprecedented $a\left({ }^{45} \mathrm{Sc}\right)$ value originates from the large contribution of $4 \mathrm{~s}$ atomic orbitals of $\mathrm{Sc}$ to the $\mathrm{Sc}-\mathrm{Sc}$ bonding $\mathrm{MO}$ in $\mathrm{Sc}_{2} @ \mathrm{C}_{82}-C_{3 \mathrm{v}}$, which transforms into a $c a .30 \%$ contribution of the $4 \mathrm{~s}$ AOs to the spin density in the cation radical. For $\mathrm{Er}_{2} @ \mathrm{C}_{82}-C_{3 \mathrm{v}}$, the metal-based oxidation leads to the formation of a unique spin system, in which local magnetic moments of Er ions derived from $4 \mathrm{f}$ electrons are coupled to each other via a single unpaired spin delocalized between two ions. The oxidation of $\mathrm{Er}_{2} @ \mathrm{C}_{82}-C_{3 \mathrm{v}}$ to $\left[\mathrm{Er}_{2} @ \mathrm{C}_{82}-C_{3 \mathrm{v}}\right]^{+}$ hence results in strong changes in the magnetization behavior. Thus, our study shows that dimetallofullerenes with a metalmetal bonding orbital provide unique possibilities for creating 
unusual spin systems which may find their use in molecular magnetism, information storage and quantum computing.

\section{Acknowledgements}

The authors acknowledge funding by the European Research Council (ERC) under the European Union's Horizon 2020 research and innovation programme (grant agreement no. 648295 "GraM3") and the National Science Foundation under NSF RUI grant 1465173. Computational resources were provided by the Center for Information Services and High Performance Computing (ZIH) in TU Dresden. The authors thank Ulrike Nitzsche for technical assistance with computational resources in IFW Dresden, Sebastian Gaß for the help in magnetic measurements, and Runshuang Lu for help in the synthesis of Er-EMFs.

\section{References}

1 M. E. Fieser, M. R. MacDonald, B. T. Krull, J. E. Bates, J. W. Ziller, F. Furche and W. J. Evans, J. Am. Chem. Soc., 2015, 137, 369-382.

2 M. R. MacDonald, J. E. Bates, J. W. Ziller, F. Furche and W. J. Evans, J. Am. Chem. Soc., 2013, 135, 9857-9868.

3 K. R. Meihaus, M. E. Fieser, J. F. Corbey, W. J. Evans and J. R. Long, J. Am. Chem. Soc., 2015, 137, 9855-9860.

4 A. A. Popov, S. Yang and L. Dunsch, Chem. Rev., 2013, 113, 5989-6113.

5 X. Lu, L. Feng, T. Akasaka and S. Nagase, Chem. Soc. Rev., 2012, 41, 7723-7760.

6 T. Wang and C. Wang, Acc. Chem. Res., 2014, 47, 450-458.

7 A. Rodriguez-Fortea, A. L. Balch and J. M. Poblet, Chem. Soc. Rev., 2011, 40, 3551-3563.

8 A. A. Popov, S. M. Avdoshenko, A. M. Pendás and L. Dunsch, Chem. Commun., 2012, 48, 8031-8050.

9 H. Kurihara, X. Lu, Y. Iiduka, N. Mizorogi, Z. Slanina, T. Tsuchiya, S. Nagase and T. Akasaka, Chem. Commun., 2012, 48, 1290-1292.

10 T. Suzuki, Y. Maruyama, T. Kato, K. Kikuchi, Y. Nakao, Y. Achiba, K. Kobayashi and S. Nagase, Angew. Chem., Int. Ed. Engl., 1995, 34, 1094-1096.

11 X. Lu, H. Nikawa, T. Nakahodo, T. Tsuchiya, M. O. Ishitsuka, Y. Maeda, T. Akasaka, M. Toki, H. Sawa, Z. Slanina, N. Mizorogi and S. Nagase, J. Am. Chem. Soc., 2008, 130, 9129-9136.

12 B. P. Cao, T. Wakahara, T. Tsuchiya, M. Kondo, Y. Maeda, G. M. A. Rahman, T. Akasaka, K. Kobayashi, S. Nagase and K. Yamamoto, J. Am. Chem. Soc., 2004, 126, 9164-9165.

13 M. Yamada, N. Mizorogi, T. Tsuchiya, T. Akasaka and S. Nagase, Chem. - Eur. J., 2009, 15, 9486-9493.

14 T. Kato, J. Mol. Struct., 2007, 838, 84-88.

15 L. Bao, M. Chen, C. Pan, T. Yamaguchi, T. Kato, M. M. Olmstead, A. L. Balch, T. Akasaka and X. Lu, Angew. Chem., Int. Ed., 2016, 55, 4242-4246.
16 M. Yamada, H. Kurihara, M. Suzuki, M. Saito, Z. Slanina, F. Uhlik, T. Aizawa, T. Kato, M. M. Olmstead, A. L. Balch, Y. Maeda, S. Nagase, X. Lu and T. Akasaka, J. Am. Chem. Soc., 2015, 137, 232-238.

17 T. Yang, X. Zhao and E. Osawa, Chem. - Eur. J., 2011, 17, 10230-10234.

18 S. T. Liddle, Molecular Metal-Metal Bonds, Wiley-VCH Verlag $\mathrm{GmbH} \&$ Co. KGaA, 2015.

19 A. Kalemos, I. G. Kaplan and A. Mavridis, J. Chem. Phys., 2010, 132, 024309-024307.

20 C. Camacho, H. A. Witek and R. Cimiraglia, J. Chem. Phys., 2010, 132, 244306-244309.

21 X. Cao and M. Dolg, Theor. Chem. Acc., 2002, 108, 143-149.

22 M. Dolg, H. Stoll and H. Preuss, J. Mol. Struct. (THEOCHEM), 1992, 277, 239-249.

23 M. Yamada, H. Kurihara, M. Suzuki, J. D. Guo, M. Waelchli, M. M. Olmstead, A. L. Balch, S. Nagase, Y. Maeda, T. Hasegawa, X. Lu and T. Akasaka, J. Am. Chem. Soc., 2014, 136, 7611-7614.

24 T. Miyazaki, R. Sumii, H. Umemoto, H. Okimoto, Y. Ito, T. Sugai, H. Shinohara, T. Zaima, H. Yagi and S. Hino, Chem. Phys., 2012, 397, 87-91.

25 H. Okimoto, R. Kitaura, T. Nakamura, Y. Ito, Y. Kitamura, T. Akachi, D. Ogawa, N. Imazu, Y. Kato, Y. Asada, T. Sugai, H. Osawa, T. Matsushita, T. Muro and H. Shinohara, J. Phys. Chem. C, 2008, 112, 6103-6109.

26 Y. Ito, T. Okazaki, S. Okubo, M. Akachi, Y. Ohno, T. Mizutani, T. Nakamura, R. Kitaura, T. Sugai and H. Shinohara, ACS Nano, 2007, 1, 456-462.

27 J. Wang and S. Irle, ECS Meeting Abstracts, 2011, 1101, 1782.

28 A. L. Svitova, K. Ghiassi, C. Schlesier, K. Junghans, Y. Zhang, M. Olmstead, A. Balch, L. Dunsch and A. A. Popov, Nat. Commun., 2014, 5, 3568, DOI: 3510.1038/ncomms4568.

29 N. Tagmatarchis, E. Aslanis, K. Prassides and H. Shinohara, Chem. Mater., 2001, 13, 2374-2379.

30 R. S. Ruoff, D. S. Tse, R. Malhotra and D. C. Lorents, J. Phys. Chem., 1993, 97, 3379-3383.

31 X. H. Zhou, Z. N. Gu, Y. Q. Wu, Y. L. Sun, Z. X. Jin, Y. Xiong, B. Y. Sun, Y. Wu, H. Fu and J. Z. Wang, Carbon, 1994, 32, 935-937.

32 M. D. Diener and J. M. Alford, Nature, 1998, 393, 668-671.

33 S. Stevenson, K. A. Rottinger and J. S. Field, Dalton Trans., 2014, 43, 7435-7441.

34 S. Stevenson, G. Rice, T. Glass, K. Harich, F. Cromer, M. R. Jordan, J. Craft, E. Hadju, R. Bible, M. M. Olmstead, K. Maitra, A. J. Fisher, A. L. Balch and H. C. Dorn, Nature, 1999, 401, 55-57.

35 S. Stevenson, K. Harich, H. Yu, R. R. Stephen, D. Heaps, C. Coumbe and J. P. Phillips, J. Am. Chem. Soc., 2006, 128, 8829-8835.

36 S. Stevenson, M. A. Mackey, C. E. Coumbe, J. P. Phillips, B. Elliott and L. Echegoyen, J. Am. Chem. Soc., 2007, 129, 6072-6073.

37 S. Stevenson, C. B. Rose, A. A. Robson, D. T. Heaps and J. P. Buchanan, Fullerenes, Nanotubes, Carbon Nanostruct., 2014, 22, 182-189. 
38 S. Stevenson, H. R. Thompson, K. D. Arvola, K. B. Ghiassi, M. M. Olmstead and A. L. Balch, Chem. - Eur. J., 2015, 21, 10362-10368.

39 S. Stevenson, M. A. Mackey, J. E. Pickens, M. A. Stuart, B. S. Confait and J. P. Phillips, Inorg. Chem., 2009, 48, 11685-11690.

40 S. Stevenson and K. A. Rottinger, Inorg. Chem., 2013, 52, 9606-9612.

41 S. Stevenson, K. A. Rottinger, M. Fahim, J. S. Field, B. R. Martin and K. D. Arvola, Inorg. Chem., 2014, 53, 12939-12946.

42 K. Akiyama, T. Hamano, Y. Nakanishi, E. Takeuchi, S. Noda, Z. Wang, S. Kubuki and H. Shinohara, J. Am. Chem. Soc., 2012, 134, 9762-9767.

43 Z. Wang, Y. Nakanishi, S. Noda, K. Akiyama and H. Shinohara, J. Phys. Chem. C, 2012, 116, 25563-25567.

44 I. Bucsi, R. Aniszfeld, T. Shamma, G. K. S. Prakash and G. A. Olah, Proc. Natl. Acad. Sci. U. S. A., 1994, 91, 9019-9021.

45 K. Tan, X. Lu and C.-R. Wang, J. Phys. Chem. B, 2006, 110, 11098-11102.

46 T.-S. Wang, N. Chen, J.-F. Xiang, B. Li, J.-Y. Wu, W. Xu, L. Jiang, K. Tan, C.-Y. Shu, X. Lu and C.-R. Wang, J. Am. Chem. Soc., 2009, 131, 16646-16647.

47 C. B. Kah, J. Nathaniel, K. Suggs and X.-Q. Wang, J. Phys. Chem. C, 2010, 114, 13017-13019.

48 Y. Feng, T. Wang, J. Wu, Z. Zhang, L. Jiang, H. Han and C. Wang, Chem. Commun., 2014, 50, 12166-12168.

49 M. M. Olmstead, H. M. Lee, S. Stevenson, H. C. Dorn and A. L. Balch, Chem. Commun., 2002, 2688-2689.

50 M. M. Olmstead, A. de Bettencourt-Dias, S. Stevenson, H. C. Dorn and A. L. Balch, J. Am. Chem. Soc., 2002, 124, 4172-4173.

51 X. Lu, K. Nakajima, Y. Iiduka, H. Nikawa, N. Mizorogi, Z. Slanina, T. Tsuchiya, S. Nagase and T. Akasaka, J. Am. Chem. Soc., 2011, 133, 19553-19558.

52 N. Chen, M. N. Chaur, C. Moore, J. R. Pinzon, R. Valencia, A. Rodriguez-Fortea, J. M. Poblet and L. Echegoyen, Chem. Commun., 2010, 46, 4818-4820.

53 T. Inoue, T. Tomiyama, T. Sugai, T. Okazaki, T. Suematsu, N. Fujii, H. Utsumi, K. Nojima and H. Shinohara, J. Phys. Chem. B, 2004, 108, 7573-7579.

54 L. Dunsch, S. Yang, L. Zhang, A. Svitova, S. Oswald and A. A. Popov, J. Am. Chem. Soc., 2010, 132, 5413-5421.

55 Y. Iiduka, T. Wakahara, K. Nakajima, T. Tsuchiya, T. Nakahodo, Y. Maeda, T. Akasaka, N. Mizorogi and S. Nagase, Chem. Commun., 2006, 2057-2059.

56 Y. Takano, R. Tashita, M. Suzuki, S. Nagase, H. Imahori and T. Akasaka, J. Am. Chem. Soc., 2016, 138, 8000-8006.

57 M. Yamada, T. Wakahara, T. Tsuchiya, Y. Maeda, T. Akasaka, N. Mizorogi and S. Nagase, J. Phys. Chem. A, 2008, 112, 7627-7631.

58 M. Yamada, T. Wakahara, Y. Lian, T. Tsuchiya, T. Akasaka, M. Waelchli, N. Mizorogi, S. Nagase and K. M. Kadish, J. Am. Chem. Soc., 2006, 128, 1400-1401.

59 Y. Zhang, D. Krylov, M. Rosenkranz, S. Schiemenz and A. A. Popov, Chem. Sci., 2015, 6, 2328-2341.
60 Y. Zhang, D. Krylov, S. Schiemenz, M. Rosenkranz, R. Westerstrom, J. Dreiser, T. Greber, B. Buchner and A. A. Popov, Nanoscale, 2014, 6, 11431-11438.

61 Y. Zhang, S. Schiemenz, A. A. Popov and L. Dunsch, J. Phys. Chem. Lett., 2013, 4, 2404-2409.

62 D. N. Laikov and Y. A. Ustynuk, Russ. Chem. Bull., 2005, 54, 820-826.

63 J. P. Perdew, K. Burke and M. Ernzerhof, Phys. Rev. Lett., 1996, 77, 3865-3868.

64 J. VandeVondele, M. Krack, F. Mohamed, M. Parrinello, T. Chassaing and J. Hutter, Comput. Phys. Commun., 2005, 167, 103-128.

65 J. Hutter, M. Iannuzzi, F. Schiffmann and J. VandeVondele, WIREs Comput. Mol. Sci., 2014, 4, 15-25.

66 N. F. Chilton, R. P. Anderson, L. D. Turner, A. Soncini and K. S. Murray, J. Comput. Chem., 2013, 34, 1164-1175.

67 L. F. Chibotaru and L. Ungur, J. Chem. Phys., 2012, 137, 064112.

68 F. Aquilante, J. Autschbach, R. K. Carlson, L. F. Chibotaru, M. G. Delcey, L. De Vico, I. F. Galván, N. Ferré, L. M. Frutos, L. Gagliardi, M. Garavelli, A. Giussani, C. E. Hoyer, G. Li Manni, H. Lischka, D. Ma, P. Å. Malmqvist, T. Müller, A. Nenov, M. Olivucci, T. B. Pedersen, D. Peng, F. Plasser, B. Pritchard, M. Reiher, I. Rivalta, I. Schapiro, J. Segarra-Martí, M. Stenrup, D. G. Truhlar, L. Ungur, A. Valentini, S. Vancoillie, V. Veryazov, V. P. Vysotskiy, O. Weingart, F. Zapata and R. Lindh, J. Comput. Chem., 2016, 37, 506-541.

69 W. Humphrey, A. Dalke and K. Schulten, J. Mol. Graphics, 1996, 14, 33-38.

70 A. A. Popov, S. M. Avdoshenko, G. Cuniberti and L. Dunsch, J. Phys. Chem. Lett., 2011, 1592-1600.

71 D. V. Konarev, L. V. Zorina, S. S. Khasanov, A. A. Popov, A. Otsuka, H. Yamochi, G. Saito and R. N. Lyubovskaya, Chem. Commun., 2016, 52, 10763-10766.

72 Y. Ma, T. Wang, J. Wu, Y. Feng, H. Li, L. Jiang, C. Shu and C. Wang, J. Phys. Chem. Lett., 2013, 4, 464-467.

73 B. Q. Mercado, N. Chen, A. Rodriguez-Fortea, M. A. Mackey, S. Stevenson, L. Echegoyen, J. M. Poblet, M. M. Olmstead and A. L. Balch, J. Am. Chem. Soc., 2011, 133, 67526760 .

74 Y. Iiduka, T. Wakahara, K. Nakajima, T. Nakahodo, T. Tsuchiya, Y. Maeda, T. Akasaka, K. Yoza, M. T. H. Liu, N. Mizorogi and S. Nagase, Angew. Chem., Int. Ed., 2007, 46, 5562-5564.

75 Q. Tang, L. Abella, Y. Hao, X. Li, Y. Wan, A. RodríguezFortea, J. M. Poblet, L. Feng and N. Chen, Inorg. Chem., 2016, 55, 1926-1933.

76 S. Yang, A. A. Popov and L. Dunsch, Angew. Chem., Int. Ed., 2008, 47, 8196-8200.

77 T. Zuo, L. Xu, C. M. Beavers, M. M. Olmstead, W. Fu, T. D. Crawford, A. L. Balch and H. C. Dorn, J. Am. Chem. Soc., 2008, 130, 12992-12997.

78 A. A. Popov, N. Chen, J. R. Pinzón, S. Stevenson, L. A. Echegoyen and L. Dunsch, J. Am. Chem. Soc., 2012, 134, 19607-19618. 
79 W. Weltner, D. McLeod and P. H. Kasai, J. Chem. Phys., 1967, 46, 3172-3184.

80 F. Neese, WIREs Comput. Mol. Sci., 2012, 2, 73-78.

81 F. Neese, J. Chem. Phys., 2005, 122, 034107.
82 D. Kivelson, J. Chem. Phys., 1960, 33, 1094-1106.

83 P. H. Rieger, Electron Spin Resonance. Analysis and Interpretation, The Royal Society of Chemistry, Cambridge, 2007. 